\title{
Synaptic SAP97 Isoforms Regulate AMPA Receptor Dynamics and Access to Presynaptic Glutamate
}

\author{
Clarissa L. Waites, ${ }^{1 \star}$ Christian G. Specht, ${ }^{1 \star}$ Kai Härtel, ${ }^{2}$ Sergio Leal-Ortiz,,${ }^{1}$ David Genoux, ${ }^{2}$ Dong Li, ${ }^{2}$ \\ Renaldo C. Drisdel, ${ }^{3}$ Okun Jeyifous, ${ }^{1}$ Juliette E. Cheyne, ${ }^{2}$ William N. Green, ${ }^{3}$ Johanna M. Montgomery, ${ }^{2}$ and \\ Craig C. Garner ${ }^{1}$ \\ ${ }^{1}$ Department of Psychiatry and Behavioral Sciences, Nancy Pritzker Laboratory, Stanford University, Palo Alto, California 94304-5485, ${ }^{2}$ Department of \\ Physiology, University of Auckland, Auckland, New Zealand, and ${ }^{3}$ Department of Neurobiology, University of Chicago, Chicago, Illinois 60637
}

The synaptic insertion of GluR1-containing AMPA-type glutamate receptors (AMPARs) is critical for synaptic plasticity. However, mechanisms responsible for GluR1 insertion and retention at the synapse are unclear. The synapse-associated protein SAP97 directly binds GluR1 and participates in its forward trafficking from the Golgi network to the plasma membrane. Whether SAP97 also plays a role in scaffolding GluR1 at the postsynaptic membrane is controversial, attributable to its expression as a collection of alternatively spliced isoforms with ill-defined spatial and temporal distributions. In the present study, we have used live imaging and electrophysiology to demonstrate that two postsynaptic, N-terminal isoforms of SAP97 directly modulate the levels, dynamics, and function of synaptic GluR1-containing AMPARs. Specifically, the unique N-terminal domains confer distinct subsynaptic localizations onto SAP97, targeting the palmitoylated $\alpha$-isoform to the postsynaptic density (PSD) and the L27 domain-containing $\beta$-isoform primarily to non-PSD, perisynaptic regions. Consequently, $\alpha$ - and $\beta$ SAP97 differentially influence the subsynaptic localization and dynamics of AMPARs by creating binding sites for GluR1-containing receptors within their respective subdomains. These results indicate that $\mathrm{N}$-terminal splicing of SAP97 can control synaptic strength by regulating the distribution of AMPARs and, hence, their responsiveness to presynaptically released glutamate.

\section{Introduction}

The activity-dependent insertion and removal of AMPA-type glutamate receptors (AMPARs) at the postsynaptic density (PSD) appears to underlie neuronal plasticity, providing a molecular basis for learning and memory (Bredt and Nicoll, 2003; Malenka and Bear, 2004). Of particular interest are mechanisms regulating the synaptic recruitment and anchoring of the GluR1 subunit of AMPARs, because of its demonstrated importance for the expression of long-term potentiation (Malinow and Malenka, 2002; Boehm et al., 2006; Ehrlich et al., 2007). However, functional redundancy among the numerous AMPAR-binding partners and the inability to accurately define the spatial and temporal context in which specific interactions occur have made these

Received Sept. 16, 2008; revised Feb. 20, 2009; accepted Feb. 22, 2009.

This work was supported by National Institutes of Health (NIH) Grants DA016758 (to C.C.G.) and NS043782, DA13602, and DA019695 (to W.N.G.), NIH National Research Service Award (to C.L.W.), Deutsche Forschungsgemeinschaft Postdoctoral Fellowship (to C.G.S.), and The Faculty Research Development Fund (University of Auckland; to J.M.M.). We thank Noam Ziv and Joseph Specht for their advice on statistical analysis and curve fitting, John Perrino for his help with immuno-EM, Oliver Schlüter and Weifeng Xu for some SAP97 expression constructs, and Richard Reimer for VGLUT1 antibody.

${ }^{*}$ C.L.W. and C.G.S. contributed equally to this work.

Correspondence should be addressed to Dr. Craig C. Garner, Department of Psychiatry and Behavioral Sciences, Nancy Pritzker Laboratory, Stanford University, 1201 Welch Road, Palo Alto, CA 94304-5485. E-mail: cgarner@stanford.edu.

C. G. Specht's present address: Biologie Cellulaire de la Synapse, Ecole Normale Superieure, 46 rue d'Ulm, 75005 Paris, France.

DOI:10.1523/JNEUROSCI.4431-08.2009

Copyright $\odot 2009$ Society for Neuroscience $\quad$ 0270-6474/09/294332-14\$15.00/0 mechanisms unclear (Barry and Ziff, 2002; Ehrlich et al., 2007; Shepherd and Huganir, 2007; Ziff, 2007).

One identified binding partner of GluR1 is SAP97, a member of the discs-large family of membrane-associated guanylate kinases (Leonard et al., 1998; Cai et al., 2002; von Ossowski et al., 2006). However, SAP97's role in the trafficking and synaptic localization of AMPARs is controversial. Supporting a possible role in synaptic transmission, overexpression of SAP97 has been shown to enhance AMPAR miniature EPSC frequency (Rumbaugh et al., 2003) or amplitude (Nakagawa et al., 2004) and shRNA-mediated knockdown to reduce AMPAR surface expression and EPSC amplitude (Nakagawa et al., 2004). However, other studies have reported that overexpression or loss of SAP97 had no effect on AMPAR-mediated neurotransmission (Klöcker et al., 2002; Schnell et al., 2002; Ehrlich and Malinow, 2004; Schlüter et al., 2006). This issue is further complicated by a study showing that SAP97 only interacts with GluR1 during its forward trafficking to the plasma membrane (Sans et al., 2001), suggesting that SAP97 acts on GluR1 solely in steps before its synaptic insertion.

Much of this controversy stems from the molecular diversity of SAP97, created by extensive alternative splicing, and a general lack of knowledge about the subcellular distributions and functions of individual isoforms (Montgomery et al., 2004). Alternative splicing occurs between the N-terminal L27 domain and the first PDZ domain of SAP97 and/or between its SH3 and guanylate kinase domains (see Fig. 1A) (Müller et al., 1995; Mori et al., 1998; McLaughlin et al., 2002). A recent study reported the existence of yet another isoform, termed $\alpha$ SAP97, in which the pro- 
totypic N-terminal L27 domain is replaced with a putative palmitoylation motif (see Fig. 1A) (Schlüter et al., 2006), conferring significant structural and functional redundancy with PSD-95 (Topinka and Bredt, 1998). For instance, overexpression of $\alpha$ SAP97 was shown to enhance the synaptic levels of AMPARs and to compensate for the shRNA-mediated loss of PSD-95 in organotypic slices (Schlüter et al., 2006). However, this study did not explore whether $\alpha$ SAP97 physically directed the insertion or the retention of these receptors within the PSD. Intriguingly, the L27 domain-containing $\beta$-isoform of SAP97 does not share these properties (Müller et al., 1995; Lee et al., 2002; Schlüter et al., 2006), indicating that splicing endows SAP97 isoforms with different characteristics. An obvious missing piece of the puzzle is when and where SAP97 isoforms interact with GluR1 and whether they only function at trafficking steps before the synaptic recruitment of AMPARs, as suggested previously (Sans et al., 2001; Esteban, 2007).

In the present study, we have sought to resolve this controversy by evaluating the spatial and kinetic properties of two $\mathrm{N}$-terminal SAP97 isoforms and by studying their effects on the distribution, dynamics, and function of synaptic GluR1containing AMPARs. Our data show that $\alpha$ - and $\beta$ SAP97 are localized within distinct domains of dendritic spines, where they influence not only the cell-surface accumulation and exchange kinetics of GluR1-containing AMPARs, but also the access of these receptor to synaptic glutamate. Thus, our data suggest that $\alpha$ - and $\beta$ SAP97 can directly influence the recruitment, kinetics, and function of synaptic AMPARs within the PSD.

\section{Materials and Methods}

\section{Hippocampal culture}

Rat primary hippocampal cultures were prepared using a modified Banker culture protocol (Banker and Goslin, 1998). Briefly, neurons from embryonic (E18-E19) Sprague Dawley rat hippocampi were dissociated in $0.05 \%$ trypsin and plated at a density of 165 cells $/ \mathrm{mm}^{2}$ on poly-L-lysine-coated coverslips. One hour after plating, coverslips were inverted over a glial feeder layer and maintained in Neurobasal medium with B27 and 2 mM GlutaMAX (Invitrogen).

\section{Expression constructs}

$\beta$ SAP97 containing the I1b, I3, and I5 domains was fused at its C terminus with enhanced green fluorescent protein (EGFP) and subcloned into

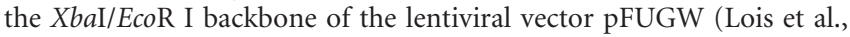
2002) to generate the plasmid pFU-rSAP97I3-EG (EMBL accession number AM710297; http://www.ebi.ac.uk/embl) for expression of $\beta S A P 97-E G F P . \alpha$ SAP97-EGFP and $\Delta$ SAP97-EGFP are constructed similarly but have alternative $\mathrm{N}$ termini: $\alpha$ SAP97-EGFP starts with the palmitoylation sequence MDCLCIVTTK; $\triangle$ SAP97-EGFP lacks this sequence and begins with exon 2 (MKYRY...). The expression constructs for rat $\alpha$ SAP97-EGFP, $\alpha$ SAP97-EGFP with short hairpin to PSD-95 (sh95), and EGFP- $\beta$ SAP97 with sh95 were gifts from Robert Malenka (Stanford University, Stanford, CA) (Schlüter et al., 2006). An $\mathrm{N}$-terminally tagged EGFP- $\beta$ SAP97 construct (pFU-EG-rSAP97I3, accession number AM710296) was used as control in the PSD-95 knockdown experiments. Monomeric cherry $(\mathrm{mCh})$-tagged GluR1 was created by inserting $\mathrm{mCh}$ between a GluR6 signal peptide and the $\mathrm{N}$ terminus of GluR1 in the lentiviral vector pFUGW. The pFUGW-based constructs were used for transfection or to generate lentivirus for infection of primary neurons. Viruses were produced as described previously (LealOrtiz et al., 2008) (see also supplemental Methods, available at www. jneurosci.org as supplemental material). Neurons were infected at day in vitro (DIV) 0-2 and used for experiments between DIV 14-17.

\section{Transfection}

Cultured neurons were transfected by calcium phosphate precipitation at DIV 7-9 and used for experiments at DIV 12-14. Briefly, for each coverslip, $2 \mu \mathrm{g}$ DNA and $7.5 \mu \mathrm{l}$ of $2 \mathrm{M} \mathrm{CaCl}_{2}$ in $60 \mu \mathrm{l}$ volume was added dropwise to $60 \mu \mathrm{l} 2 \times \mathrm{HBS}\left(274 \mathrm{~mm} \mathrm{NaCl}, 10 \mathrm{~mm} \mathrm{KCl}, 1.4 \mathrm{~mm} \mathrm{Na}_{2} \mathrm{HPO}_{4}\right.$, $15 \mathrm{~mm}$ glucose, $42 \mathrm{~mm}$ HEPES, pH 7.1), incubated for $20 \mathrm{~min}$, then added to cultured neurons in $1 \mathrm{ml}$ conditioned medium containing 10 $\mu \mathrm{M}$ CNQX and $50 \mu \mathrm{M}$ APV. After a $20 \mathrm{~min}$ incubation at $37^{\circ} \mathrm{C}$, neurons were rinsed $3 \times$ with $2 \mathrm{ml}$ prewarmed HBSS and transferred back into culture dishes.

\section{Immunocytochemistry}

Neurons were fixed and processed for immunofluorescence as described previously (Leal-Ortiz et al., 2008). The following primary antibodies were used: VGLUT1 (1:200; gift from Dr. Richard Reimer, Stanford University, Stanford, CA), GluR1 (1:50; Calbiochem), SAP97 (1:500; Affinity BioReagents), PSD-95 (1:200; Affinity BioReagents), GluR3 (1:100; Millipore Bioscience Research Reagents), and red fluorescent protein (RFP; 1:500; MBL International). All secondary antibodies and phalloidin were from Invitrogen. Images were acquired on a Zeiss Axiovert 200M with $100 \times$ and $40 \times$ objectives (1.3 NA; Zeiss Plan Neofluar) and FITC and resorufin filter sets (Chroma Technology) using a Hamamatsu digital camera (ORCA-ER) and OpenLab software (Improvision). For highresolution confocal imaging, a Zeiss laser-scanning confocal microscope (Axiovert $100 \mathrm{M})$ with a $63 \times$ oil-immersion objective $(1.40 \mathrm{NA}$; Zeiss Plan Apochromat) and Zeiss laser-scanning microscopy 510 software 3.2 were used. Excitation wavelengths were 488, 543, and $633 \mathrm{~nm}$, and fluorescence was acquired using $500-530 \mathrm{~nm}$ bandpass and 560 and $650 \mathrm{~nm}$ long-pass filters for EGFP, Alexa 568, and Alexa 647, respectively. Laser power, amplifier gain, and offset were adjusted to accommodate the entire dynamic range of the signal.

Quantification of cell-surface GluR1 accumulation was done using OpenView software (written by N. Ziv). For each neuron analyzed, endogenous GluR1 puncta that colocalized with $\alpha-, \beta-$, or $\Delta$ SAP97-EGFP in dendritic spines were identified and their intensities measured. Intensity values for all puncta were averaged, corrected for background fluorescence, and divided by the averaged intensities of dendritic GluR1 puncta from untransfected neurons (also background subtracted) within the same field of view to obtain relative synaptic expression levels. For comparison of surface versus total mCh-GluR1, intensity values for surface GluR1 puncta that colocalized with $\alpha-, \beta-$, or $\Delta$ SAP97-EGFP in dendritic spines (labeled with RFP primary antibodies followed by Alexa 647 secondary antibodies) were measured, averaged, and divided by the values for total mCh-GluR1.

\section{Palmitoylation assay}

Palmitoylation of $\alpha$ SAP97 was assessed using a recently developed method (Drisdel and Green, 2004; Drisdel et al., 2006). See supplemental Methods, available at www.jneurosci.org as supplemental material, for details of this procedure.

\section{Immunogold electron microscopy}

Hippocampal cultures were fixed and processed for immunogold electron microscopy (EM) as described previously (Micheva et al., 2003). See supplemental Methods, available at www.jneurosci.org as supplemental material, for details of this procedure. EM images were acquired with a JEM-1230 electron microscope (JEOL) at $80 \mathrm{kV}$ accelerated voltage using a Gatan 791 charge-coupled device camera. Image acquisition and quantification of SAP97 isoform localization was performed by an experimenter blind to the isoform expressed. For each construct ( $\alpha$ - and $\beta$ SAP97-EGFP), more than 60 images were acquired, and only synapses exhibiting clear ultrastructure (i.e., presynaptic vesicles apposed to a PSD) and immunogold labeling were included in the quantification. At these sites, the contrast was adjusted to allow clear visualization of individual silver-enhanced gold particles. Under these conditions, the number of silver-enhanced gold particles clearly associated with the PSD (located within $0-50 \mathrm{~nm}$ of the outline of the PSD) or outside of the PSD (50-700 $\mathrm{nm}$ from the PSD in synaptic spines) were tabulated, expressed as fraction of total dendritic spine labeling, and compared for $\alpha$ - and $\beta$ SAP97 isoforms.

\section{Live imaging}

All live-imaging experiments were performed on a custom-built (by S. Smith and N. Ziv) scanning confocal microscope as described previously (Leal-Ortiz et al., 2008). 
Table 1. Curve fitting of FRAP data

\begin{tabular}{|c|c|c|c|c|c|}
\hline & $a(/)$ & $\tau_{1}(\min )$ & $\tau_{2}(\min )$ & $\chi^{2}$ & $\mathrm{df}$ \\
\hline$\alpha$ SAP97-GFP, lentivirus & $0.20 \pm 0.01$ & $2.9 \pm 0.4$ & $71 \pm 10$ & 6.7 & 16 \\
\hline$\beta$ SAP97-GFP, lentivirus & $0.58 \pm 0.05$ & $2.2 \pm 0.5$ & $34 \pm 14$ & 11.6 & 16 \\
\hline$\triangle$ SAP97-GFP, lentivirus & $0.72 \pm 0.03$ & $0.6 \pm 0.1$ & $10 \pm 2$ & 2.6 & 16 \\
\hline mCh-GluR1 (plus $\alpha$ SAP97-GFP) & $0.35 \pm 0.03$ & $1.5 \pm 0.4$ & $26 \pm 6$ & 10.1 & 16 \\
\hline mCh-GluR1 (plus $\beta$ SAP97-GFP) & $0.54 \pm 0.06$ & $1.4 \pm 0.4$ & $24 \pm 10$ & 9.9 & 16 \\
\hline mCh-GluR1 (plus $\triangle$ SAP97-GFP) & $0.70 \pm 0.06$ & $1.2 \pm 0.4$ & $26 \pm 17$ & 8.1 & 9 \\
\hline
\end{tabular}

Parameters were extracted as described by Tsuriel et al. (2006). Parameters include two recovery time constants $\left(\tau_{1}\right.$ and $\left.\tau_{2}\right)$ and the relative size of the fast (a) and the slow pool ( $1-a$ ). The fitted curves are in agreement with the experimental data, as judged by a $\chi^{2}$ test; /, fractional amount; $d f$, degrees of freedom.

FM4-64 loading. FM4-64 loading was performed as described previously (Leal-Ortiz et al., 2008). Briefly, presynaptic boutons were labeled with $10 \mu \mathrm{M}$ FM4-64 dye (Invitrogen) by electrical stimulation $(10 \mathrm{~Hz}$; $60 \mathrm{~s}$ ) and washed for $\sim 5$ min before imaging.

Triton extraction. For live extraction, neurons were perfused with $0.5 \%$ Triton X-100 in Tyrode's solution for 1 min. Images were acquired before and after Triton perfusion.

Latrunculin treatment. Cultured neurons were incubated in medium containing $10 \mu \mathrm{m}$ latrunculin A for $5 \mathrm{~h}$ and fixed.

Fluorescence recovery after photobleaching analysis. SAP97-EGFP puncta were bleached to $\sim 20 \%$ of their initial fluorescence by multiple scanning passes (15-20) of a high intensity laser beam (488 nm wavelength) at high magnification. The fluorescence recovery was imaged for $30 \mathrm{~min}$, every $30 \mathrm{~s}$ for the first $7 \mathrm{~min}$ after bleaching and every $5 \mathrm{~min}$ thereafter. Similarly, fluorescence recovery after photobleaching (FRAP) was performed on mCherry-tagged GluR1 with a $514 \mathrm{~nm}$ laser line.

2-Bromopalmitate treatment. Neuron cultures were incubated in medium containing $10 \mu \mathrm{M}$ 2-bromopalmitate overnight ( $\sim 20 \mathrm{~h})$. FRAP analysis was then performed in Tyrode's solution in the presence of 10 $\mu \mathrm{M}$ 2-bromopalmitate.

Antibody crosslinking. Before FRAP experiments, coverslips were incubated for $10 \mathrm{~min}$ at room temperature with polyclonal anti-RFP antibodies (MBL International; 1:100 in Tyrode's solution) or anti-GluR1 antibodies (1:50; Calbiochem), briefly washed, and incubated for $10 \mathrm{~min}$ with anti-rabbit secondary antibody (Invitrogen; 1:100). After another brief wash, coverslips were mounted for FRAP analysis.

Data analysis/curve fitting. For each time point, $t$, FRAP intensity values of all puncta were expressed relative to baseline fluorescence before bleaching $\left(I_{\text {pre }}\right)$. To control for the continuous photobleaching during image acquisition, the intensity of bleached puncta $\left(I_{t} / I_{\text {pre }}\right)$ was normalized against that of nonbleached puncta $\left(I_{\mathrm{nb}, \mathrm{t}} / I_{\mathrm{nb}, \mathrm{pre}}\right)$ at the same time point and in the same field of view according to the following equation:

$$
F_{\mathrm{t}}=\frac{I_{\mathrm{t}} \cdot I_{\mathrm{nb}, \mathrm{pre}}}{I_{\mathrm{pre}} \cdot I_{\mathrm{nb}, \mathrm{t}}}
$$

To allow us to calculate the means of the recovery traces for each condition, the FRAP data were further normalized to the first value after photobleaching $(t=0$; set to zero):

$$
F_{\text {norm }}=\frac{F_{\mathrm{t}}-F_{0}}{F_{\text {pre }}-F_{0}},
$$

where $F_{\text {norm }}$ is the normalized relative fluorescent intensity, $F_{\mathrm{t}}$ the intensity at time, $t, F_{0}$ at time $t=0$, and $F_{\text {pre }}=1$, the intensity before photobleaching. The normalized recovery data are summarized in supplemental Table S1, available at www.jneurosci.org as supplemental material.

Curves were fitted to the mean experimental data according to the following equation as described previously (Tsuriel et al., 2006):

$$
f(t)=a \cdot\left(1-e^{-\frac{t}{\tau_{1}}}\right)+(1-a) \cdot\left(1-e^{-\frac{t}{\tau_{2}}}\right),
$$

where $\tau_{1}$ and $\tau_{2}$ are two recovery time constants and $a$ and $(1-a)$ are the relative fraction of fluorescence in the two components (Table 1). The theoretical parameters $a, \tau_{1}$, and $\tau_{2}$ were extracted through minimizing the sum of squared residuals, using a macro written in Excel (by N. Ziv).
Whole-cell patch-clamp recordings

EPSC measurements. Whole-cell recordings were performed to examine miniature and evoked EPSCs at DIV 11-14 on dissociated hippocampal pyramidal neurons that had been transfected with $\alpha-, \beta$-, $\triangle$ SAP97-EGFP. For control recordings, miniature and evoked EPSCs were recorded from neurons expressing soluble EGFP; these did not differ from untransfected neurons (data not shown). Cultures were perfused at room temperature at a rate of $2 \mathrm{ml} / \mathrm{min}$ with artificial CSF (ACSF: $119 \mathrm{~mm} \mathrm{NaCl}, 2.5 \mathrm{~mm} \mathrm{KCl}, 1.3 \mathrm{~mm} \mathrm{MgSO}_{4}, 2.5 \mathrm{~mm} \mathrm{CaCl}_{2}, 1$ $\mathrm{mM} \mathrm{Na}_{2} \mathrm{HPO}_{4}, 26.2 \mathrm{~mm} \mathrm{NaHCO} 3,11 \mathrm{~mm}$ glucose). For mediated EPSCs (mEPSCs), ACSF also contained $1 \mu \mathrm{M}$ TTX and $100 \mu \mathrm{M}$ picrotoxin. Neurons were visualized by infrared differential interference contrast microscopy and held in voltage-clamp mode at $-65 \mathrm{mV}$ (Multiclamp; Axon) and low-pass filtered at $2 \mathrm{kHz}$. Presynaptic neurons were held in current clamp and induced to fire action potentials by brief injection of depolarizing current (typically $20-50 \mathrm{pA}$ for 20 $\mathrm{ms}$ ). Series resistance (Rs) was monitored throughout the duration of the recording and data excluded if Rs increased $>20 \%$. Internal solution consisted of the following: $120 \mathrm{~mm}$ potassium gluconate, $40 \mathrm{~mm}$ HEPES, 5 mм $\mathrm{MgCl}_{2}$, $0.3 \mathrm{~mm} \mathrm{NaGTP,} 2$ mм NaATP, 5 mм QX314 (postsynaptic cell only), pH 7.2 with potassium hydroxide. For mEPSCs, data were acquired continuously until a minimum of $100 \mathrm{mEP}-$ SCs were recorded. mEPSC events were detected with MiniAnalysis (Synaptosoft; version 6.0.3). Since the mEPSC amplitude distribution did not follow a normal distribution, the nonparametric Kolmogorov-Smirnov test (Van der Kloot, 1991) was used to determine the probability of a significant difference between current amplitudes measured in control and SAP97-transfected neurons. Evoked AMPAR-mediated EPSCs were measured as described previously (Montgomery et al., 2001; Montgomery and Madison, 2002). Baseline EPSCs in response to presynaptic action potential firing were collected at $0.1 \mathrm{~Hz}$. Online data acquisition and offline analysis or AMPAR-mediated EPSCs was performed with pClamp (Clampex v9.2). Statistical significance of changes in AMPAR EPSC amplitudes was tested using the Student's $t$ test, with the level of significance set at $p<0.05$.

Focal application of AMPA. Exogenous AMPA (1 mM) was applied from a micropipette $200 \mu \mathrm{m}$ from the dendrites of $\alpha$ - or $\beta$ SAP97-EGFPtransfected neurons with a picospritzer (pressure 2 bar; pulse $200 \mathrm{~ms}$ ). The peak amplitudes of the total surface AMPA receptor-mediated currents were measured by whole-cell patch clamp as detailed above. To verify that the exogenous AMPA was not saturating the total surface receptors and therefore preventing any increase in AMPA currents being measured, an additional application of AMPA was applied closer to the dendrites at the completion of each experiment.

\section{Results}

\section{Synaptic localization of N-terminal SAP97 isoforms}

Critical to defining the functional relationship between SAP97 and GluR1 is the precise cellular context in which this interaction occurs. Previous studies have shown that endogenous SAP97 is found throughout the somatodendritic compartment and within dendritic spines (Valtschanoff et al., 2000; Aoki et al., 2001; Sans et al., 2001; Rumbaugh et al., 2003; Regalado et al., 2006). However, as most neurons express multiple SAP97 isoforms 
A
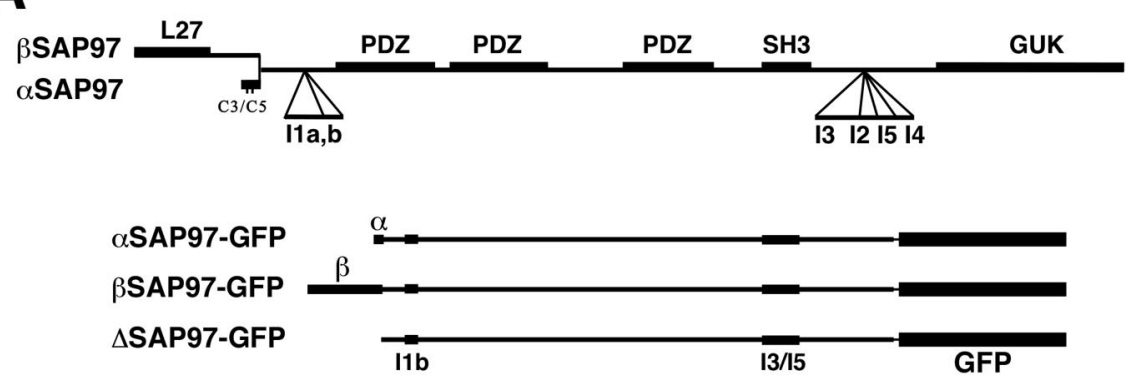

B
¿SAP97-GFP

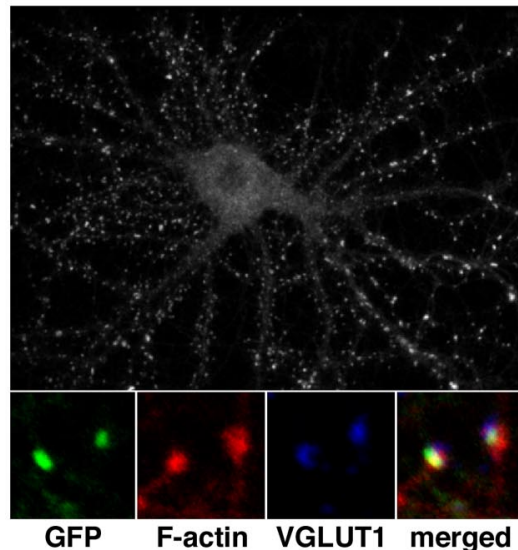

BSAP97-GFP

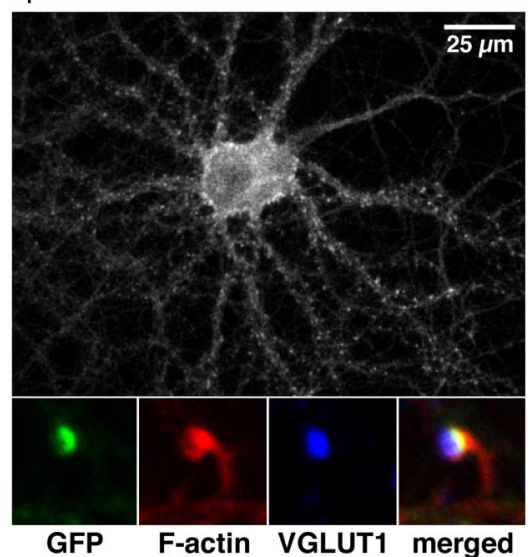

C

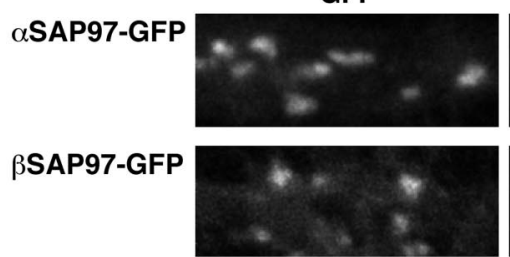

FM4-64
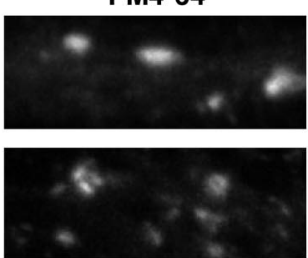

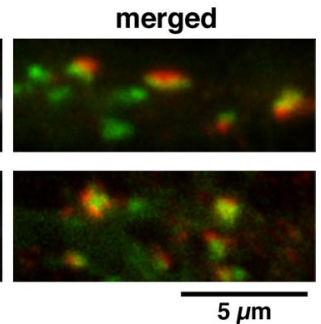

Figure 1. Subcellular localization of $\alpha$-and $\beta$ SAP97 isoforms. A, Schematic domain organization of SAP97. $\alpha$-and $\beta$-isoforms differ in their $\mathrm{N}$ termini, with the former containing a palmitoylation motif (cysteine residues $\mathrm{C} 3$ and $\mathrm{C}$ ) and the latter an L27 domain. Alternatively spliced sequences (11a, I1 b, I2, 13, I4, I5) are indicated. EGFP-tagged constructs used in this study (containing I1b, I3, and 15 inserts) are depicted below. $\boldsymbol{B}$, Lentiviral expression of $\alpha$ - and $\beta$ SAP97-EGFP in primary hippocampal neurons (DIV 16). Higher magnification insets (4.5 $\mu \mathrm{m}$ width) show colocalization of $\alpha$ - and $\beta$ SAP97-EGFP with phalloidin in spines (red) and the presynaptic vesicle marker VGLUT1 (blue). C, Colocalization of $\alpha$ - and $\beta$ SAP97-EGFP puncta with FM4-64-labeled synaptic vesicles.

the N-terminal isoforms $\alpha$ - and $\beta$ SAP97 containing the same set of additional inserts (I1b/I3/I5) (Fig. 1A).

In mature hippocampal cultures infected with lentivirus on the day of plating (DIV 0), both isoforms had punctate dendritic distributions (Fig. 1B). However, whereas $\alpha$ SAP97-EGFP was highly enriched in dendritic spines, the $\beta$-isoform was found both in spines and more diffusely throughout dendritic shafts and cell bodies (Fig. 1B,C; supplemental Fig. $\mathrm{S} 2 A, B$, available at www.jneurosci.org as supplemental material). To verify that $\alpha$ and $\beta$ SAP97-EGFP puncta in spines represented synapses, fixed neurons were stained with antibodies against a presynaptic marker (VGLUT1) and phalloidin to label filamentous actin (F-actin) (Fig. $1 B)$. This revealed that the majority of SAP97-EGFP puncta were synaptic. Moreover, live labeling of synaptic vesicles with the styryl dye FM4-64 demonstrated that most $\alpha$ - and $\beta$ SAP97-EGFP puncta were juxtaposed to functional presynaptic boutons (Fig. 1C). These data are consistent with a postsynaptic spiny localization of both SAP97 isoforms.

\section{Exchange kinetics of $\alpha$ and $\beta$ SAP97 in} dendritic spines

To evaluate whether the differences in subcellular distribution between $\alpha$ - and $\beta$ SAP97-EGFP reflected functional differences, we examined their dynamic behaviors within spines using FRAP. Here, the recovery of bleached $\alpha$ - or $\beta$ SAP97-EGFP puncta was monitored for a $30 \mathrm{~min}$ period (Fig. 2A). Strikingly, the two isoforms exhibited dramatically different recovery rates, with $<50 \%$ of $\alpha$ SAP97-EGFP fluorescence and $>80 \%$ of $\beta$ SAP97-EGFP fluorescence recovering within this time window (Fig. $2 B$; supplemental Table S1, available at www. jneurosci.org as supplemental material). These data indicate that $\alpha$ SAP97 is stably associated with postsynaptic structures while $\beta$ SAP97 is much more dynamic.

(Rumbaugh et al., 2003; Schlüter et al., 2006), and isoformspecific antibodies are lacking, resolving the spatial distributions of individual isoforms has proven elusive. Thus, we examined the distributions of individual EGFP-tagged SAP97 isoforms using lentivirus infection (Lois et al., 2002) or calcium phosphate transfection for expression in dissociated hippocampal neurons. These methods enabled expression of SAP97 isoforms at levels comparable with that of endogenous PSD-95, a closely related MAGUK protein, without significantly affecting endogenous SAP97 expression (see supplemental Results; supplemental Fig. $\mathrm{S} 1$, available at www.jneurosci.org as supplemental material). Because of their potential yet controversial roles in regulating AMPAR-mediated EPSCs (Sans et al., 2001; Rumbaugh et al., 2003; Nakagawa et al., 2004; Schlüter et al., 2006), we were specifically interested in evaluating the localization and dynamics of
To further explore these kinetics, the recovery curves were fitted using a model that assumes two exponential components of recovery with individual time constants $\tau$, as described previously (Tsuriel et al., 2006). The theoretical parameters $\tau_{1}, \tau_{2}$, and $a$ (the relative amount of fluorescence in the fast component $\tau_{1}$ ) were extracted by minimizing the sum of the squared residuals (Table 1). According to this analysis, $\alpha$ SAP97-EGFP recovery was characterized by a very slow component $\left(\tau_{2}=71 \mathrm{~min}\right)$ representing $80 \%$ of the entire fluorescence, whereas $\beta$ SAP97-EGFP had a larger fast component of recovery $\left(\tau_{1}=2.2 \mathrm{~min} / 58 \%\right)$, and the time constant of its slow component ( $\tau_{2}=34 \mathrm{~min} / 42 \%$ ) was faster than that of $\alpha$ SAP97 (Fig. 2 B, Table 1). Together, these data demonstrate that within dendritic spines, $\alpha$ - and $\beta$ SAP97 have strikingly distinct kinetic exchange properties. 
N-terminal domains of SAP97 define its kinetic properties within spines

The more restricted synaptic localization and slower exchange rate observed for $\alpha$ SAP97 compared with $\beta$ SAP97 could be attributable to the presence of its putative palmitoylation domain and/or to the lack of the L27 domain. To distinguish between these possibilities, we examined the localization and exchange kinetics of an $\mathrm{N}$-terminal deletion mutant ( $\triangle$ SAP97EGFP) lacking both the initial 10 aa residues of $\alpha$ SAP97 (including its putative palmitoylation motif) and the initial 106 residues (including the L27 domain) of BSAP97 (Fig. 1A). Lentiviral expression of $\triangle$ SAP97-EGFP revealed an expression pattern similar to that of $\beta$ SAP97-EGFP, with diffuse somatodendritic labeling and punctate labeling of spines (Fig. 3A). As with $\alpha$ - and $\beta$-isoforms, dendritic $\triangle$ SAP97-EGFP puncta colocalized with F-actin, VGLUT1, and FM4-64, demonstrating that neither $\mathrm{N}$-terminal sequence was required for the synaptic targeting of SAP97 (Fig. 3B; supplemental Fig. 2C, available at www.jneurosci.org as supplemental material). This finding is consistent with previous studies showing that the I3 insert is essential for the synaptic localization of SAP97 (Rumbaugh et al., 2003). However, using FRAP analysis, we found $\triangle$ SAP97-EGFP puncta to have very fast exchange kinetics, exhibiting near complete fluorescence recovery within $5 \mathrm{~min}$ (Fig. $3 C, D$, Table 1$)\left(\tau_{1}\right.$ $=0.6 \mathrm{~min} / 72 \%)$. Although these kinetics are significantly slower than those of freely diffusing protein (i.e., soluble EGFP), which recovers within seconds (Tsuriel et al., 2006), they indicate that $\triangle$ SAP97 is highly dynamic and that the $\mathrm{N}$-terminal sequences are necessary for establishing more stable interactions with postsynaptic structures.

The slower exchange kinetics of $\beta$ SAP97 compared with $\triangle$ SAP97 are probably the consequence of its association with other synaptic/cytoskeletal proteins through the L27 domain (Wu et al., 1998; Karnak et al., 2002; Lee et al., 2002; Wu et al., 2002; Nakagawa et al., 2004). In contrast, based on sequence homology with the $\mathrm{N}$ terminus of PSD-95, the slow exchange kinetics of $\alpha$ SAP97 likely result from palmitoylation of the conserved cysteine residues at positions 3 and 5 (Fig. $1 A$ ). To test this hypothesis, we performed two experiments. First, we directly assessed palmitoylation of $\alpha$ SAP97-EGFP in human embryonic kidney (HEK) cells using a technique whereby palmitoylated cysteine residues are biotinylated after cleavage of the palmitate group with hydroxylamine (Drisdel and Green, 2004; Drisdel et al., 2006). As shown in Figure 3E, $\alpha$ SAP97 is clearly palmitoylated, whereas $\beta$ - and $\triangle$ SAP97 exhibit no palmitoylation. Second, we measured the fluorescence recovery of $\alpha$ - and $\beta$ SAP97-EGFP puncta in neurons that had been incubated overnight with the palmitoylation inhibitor 2-bromopalmitate. This treatment dramatically increased the exchange rate of $\alpha$ SAP97 without significantly affecting that of $\beta$ SAP97 (Fig. $3 F, G$ ). Together, these experiments indicate that palmitoylation leads to the slow exchange kinetics of $\alpha$ SAP97-EGFP.

B baseline $\quad 0 \mathrm{~min}$

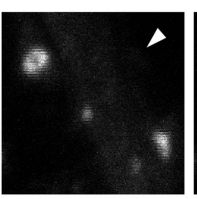

$1 \mathrm{~min}$

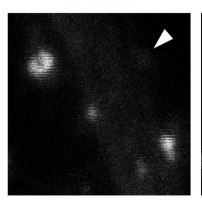

$5 \mathrm{~min}$
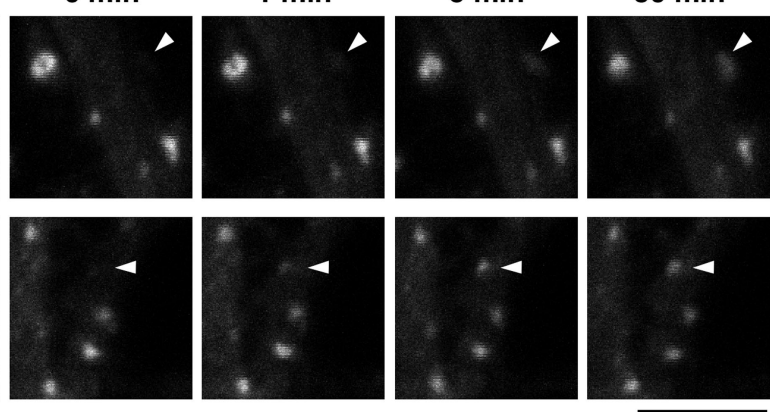

$5 \mu \mathrm{m}$

Figure 2. Synaptic exchange kinetics of $\alpha$ - and $\beta$ SAP97 isoforms. $\boldsymbol{A}$, Images of FRAP of $\alpha$ - and $\beta$ SAP97-EGFP puncta (indicated by arrowheads) on dendrites. $\boldsymbol{B}$, Fluorescence recovery of $\alpha$ - (gray) and $\beta$ SAP97-EGFP (black) puncta, normalized to the average intensity of unbleached puncta in the same field of view and set to values between 0 and 100 (see Materials and Methods). Error bars depict \pm SEM ( $n \geq 18)$. Curves were fit to the experimental data as described in Materials and Methods.

\section{Subsynaptic localization and biochemical properties of $\alpha$-,} $\beta$-, and $\Delta$ SAP97

The observed differences in FRAP exchange kinetics of $\alpha$-, $\beta$-, and $\triangle$ SAP97-EGFP suggest that each construct has distinct binding properties and/or localizations within dendritic spines. To visualize their subsynaptic localizations, we initially compared the expression patterns of $\alpha$ - and $\beta$ SAP97-EGFP within single spines to that of PSD-95, a known component of the PSD, by light-level immunofluorescence microscopy (Fig. 4A). Although $\alpha$ SAP97 precisely colocalized with PSD-95 puncta, $\beta$ SAP97 had a broader distribution, often appearing to encircle PSD-95 puncta (Fig. 4A). Although limited by the optical resolution of light microscopy, these findings suggest that $\alpha$ - and $\beta$ SAP97 may localize to distinct subdomains within spines.

To confirm this hypothesis, we analyzed the biochemical properties of $\alpha$-, $\beta$-, and $\Delta$ SAP97-EGFP at single synapses by assessing their extractability with $0.5 \%$ Triton X-100 during a live-imaging experiment (Fig. 4B). Many PSD and cytoskeletalassociated proteins are insensitive to this treatment, whereas cytoplasmic and membrane-associated proteins are solubilized and washed out (Sharma et al., 2006). By comparing the SAP97EGFP fluorescence intensity of individual synaptic puncta before and after extraction, we were able to estimate the insoluble fraction of each SAP97 construct. As expected from our FRAP experiments, the majority ( $\sim 60 \%$ ) of $\alpha$ SAP97-EGFP was Triton resistant, suggesting an association with lipids and proteins within the PSD (Fig. $4 B$ ). In contrast, only $\sim 30 \%$ of $\beta$ SAP97-EGFP and $<10 \%$ of $\triangle$ SAP97-EGFP were Triton resistant. These data indicate that approximately one-third of $\beta S A P 97$ is associated with 
A
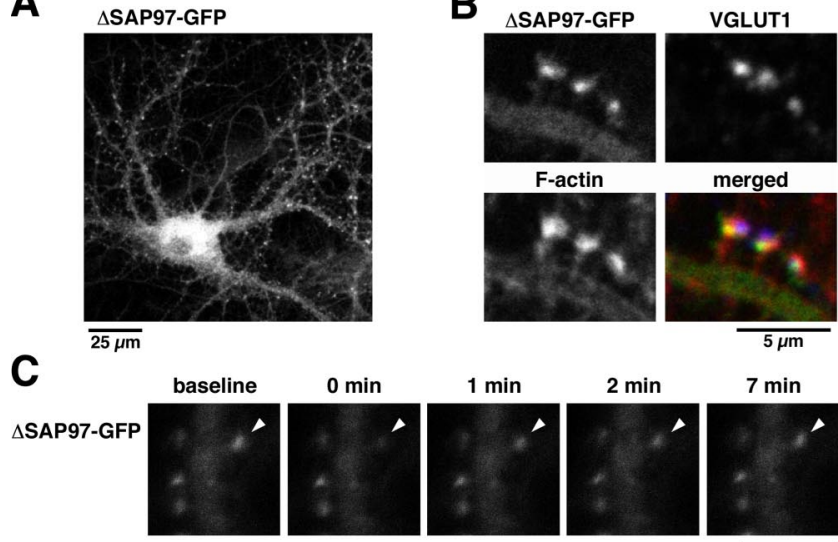

D

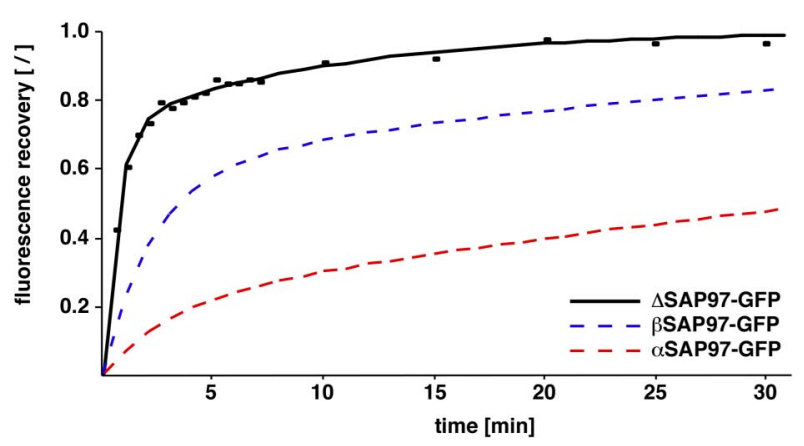

E

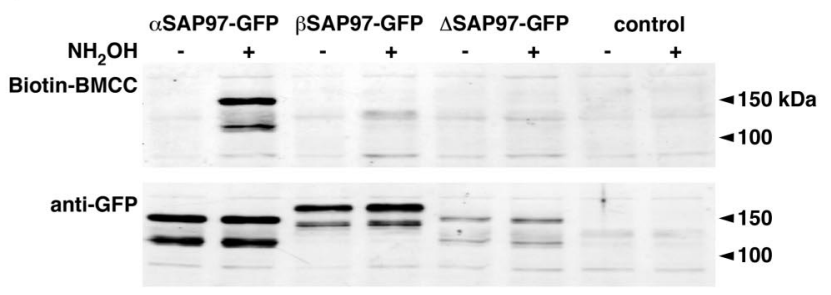

F
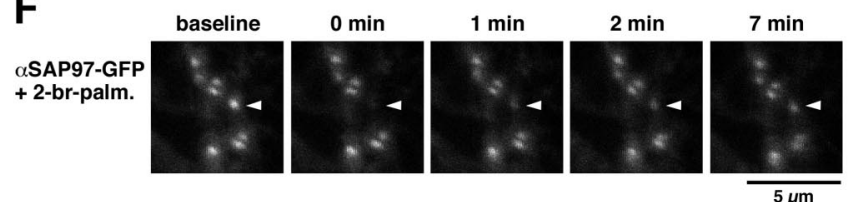

G

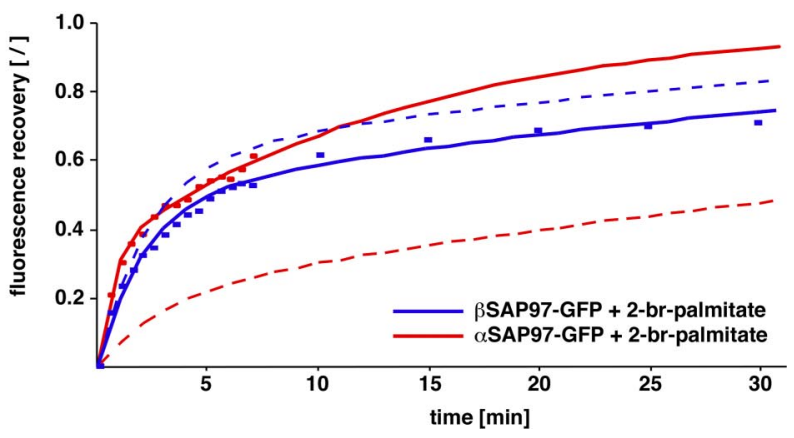

Figure 3. Role of N-terminal domains for the kinetic properties of SAP97. $\boldsymbol{A}$, Lentiviral expression of the deletion mutant $\triangle$ SAP97-EGFP in hippocampal neurons. $\boldsymbol{B}$, Colocalization of $\triangle$ SAP97EGFP with phalloidin (red) and VGLUT1 (blue). C, Images depicting fluorescence recovery of $\Delta$ SAP97-EGFP puncta. $D$, FRAP quantification of $\Delta$ SAP97-EGFP (black; $n \geq 13$ ), $\alpha S A P 97-E G F P$ (dashed red; data from Fig. $2 B$ ), and $\beta$ SAP97-EGFP (dashed blue; from Fig. $2 B$ ). $E$, Western blot of HEK cell lysates from untransfected cells (control) and those transfected with $\alpha$-, $\beta$-, or $\Delta$ SAP97-EGFP, probed with anti-GFP antibodies to detect total protein (bottom) or streptavidin-conjugated HRP to label Biotin-BMCC [1-biotinamido-4-(4' -[maleimidoethyl-cyclohexane]-carboxamido) butane] (top). Only $\alpha$ SAP97-EGFP is biotinylated after hydroxylamine $\left(\mathrm{NH}_{2} \mathrm{OH}\right)$ treatment, indicating palmitoylation of its $\mathrm{N}$-terminal cysteine residues. $\boldsymbol{F}$, Images depicting fluorescence recovery of $\alpha$ SAP97-EGFP in the presence of 2-bromopalmitate. G, FRAP curves of $\alpha$-and $\beta$ SAP97-EGFP plus 2-bromopalmitate (red solid, $n=23$; blue solid, $n=28$, respectively), or untreated (dashed lines; same data as $\boldsymbol{D}$ and Fig. $2 B$ ).

the cortical cytoskeleton and/or the PSD, whereas a majority of $\triangle$ SAP97 is associated with neither. Intriguingly, the Tritonresistant fractions of $\alpha-, \beta$-, and $\Delta$ SAP97-EGFP paralleled the fractional amounts in their slow kinetic pools (80, 40, and 30\%, respectively) (compare Fig. $4 B$, Table 1 ).

We next examined whether the localization of $\alpha^{-}, \beta-$, and $\Delta$ SAP97-EGFP was dependent on the actin cytoskeleton. We found that acute $(15 \mathrm{~min})$ depolymerization of F-actin with latrunculin A had no effect on any of the three constructs, indicating that their localizations are not directly dependent on the dynamic assembly of F-actin (supplemental Results; supplemental Fig. S3B, available at www.jneurosci.org as supplemental material). Since dendritic spines also contain an actin/spectrin cortical cytoskeleton that is more resistant to F-actin destabilization, we evaluated whether a $5 \mathrm{~h}$ latrunculin treatment, known to disrupt this pool of actin (Reuver and Garner, 1998; Allison et al., 2000; Rumbaugh et al., 2003), altered the synaptic associations of $\alpha$-, $\beta$-, and $\triangle$ SAP97 molecules. Here, we found a reduction of both $\beta$ - and $\Delta$ SAP97-EGFP fluorescence, whereas $\alpha$ SAP97-EGFP puncta remained mostly unaffected (Fig. 4C; supplemental Fig. $\mathrm{S} 3 C$, available at www.jneurosci.org as supplemental material), again indicating that $\alpha$ - and $\beta$ SAP97 are associated with biochemically distinct compartments within dendritic spines.

To more closely examine the subsynaptic distributions of $\alpha$ and $\beta$ SAP97, we performed silver-enhanced immunogold EM of neurons expressing $\alpha$ - or $\beta$ SAP97-EGFP (Fig. $4 D$; supplemental Results; supplemental Fig. S4, available at www.jneurosci.org as supplemental material). Quantitative analysis of EM micrographs revealed that within spines, $\sim 50 \%$ of silver-enhanced gold particles labeling $\alpha$ SAP97-EGFP were associated with the PSD, whereas only $\sim 30 \%$ of gold particles labeling $\beta$ SAP97EGFP could be detected at the PSD (Fig. $4 E$ ). In contrast, the majority $(\sim 70 \%)$ of gold particles labeling $\beta$ SAP97-EGFP appeared at other locations, most commonly near the spine plasma membrane or within the cytoplasm, that were often adjacent to the PSD (Fig. 4D,E; supplemental Fig. S4, available at www. jneurosci.org as supplemental material). These data are consistent with other immuno-EM studies showing that L27 domain containing SAP97 isoforms have a predominantly peripheral PSD distribution (Aoki et al., 2001; DeGiorgis et al., 2006). Together with the biochemical assays, these results indicate that $\alpha$ SAP97 is a core component of the PSD, whereas $\beta$ SAP97 has a broader, primarily non-PSD distribution within spines.

\section{SAP97 isoform-specific regulation of GluR1 targeting and exchange kinetics}

SAP97 directly binds the AMPAR subunit GluR1 (Leonard et al., 1998; Cai et al., 2002) (see also supplemental Results; supplemental Fig. S5 A, B, available at www.jneurosci.org as supplemental material) and promotes its cell-surface localization (Sans et al., 2001). We therefore examined whether the distinct biochemical and kinetic properties of $\alpha$ - and $\beta$ SAP97-EGFP differentially affected the synaptic localization and dynamics of GluR1. Initially, we examined the cell-surface levels of endogenous GluR1 
A
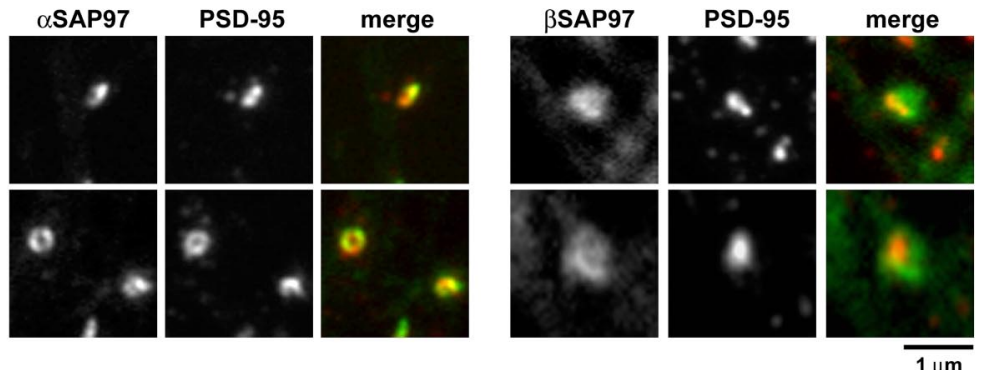

B

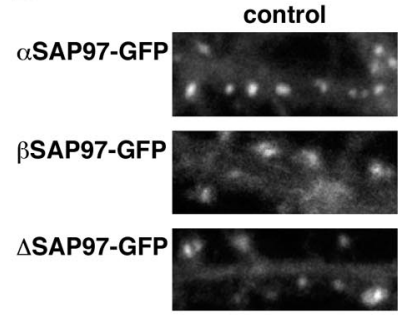

C

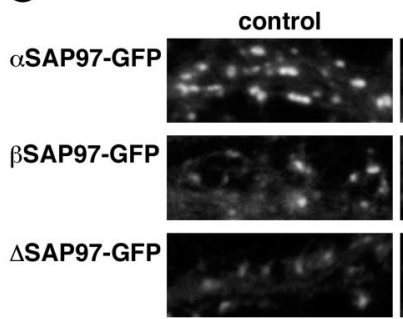

D

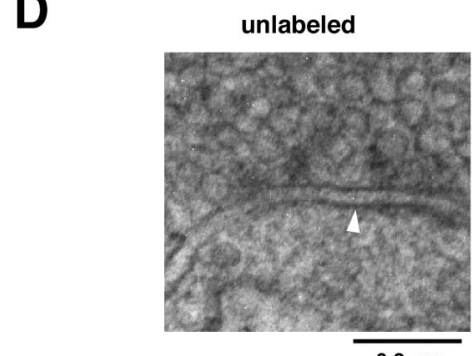

E

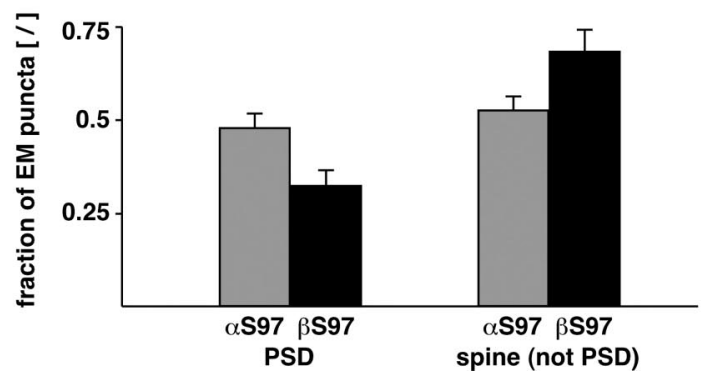

Figure 4. Subsynaptic localization of SAP97-EGFP isoforms. $A$, Single spines of lentivirus-infected neurons expressing $\alpha$ SAP97-EGFP (left panels; green) or $\beta$ SAP97-EGFP (right panels; green) and stained with PSD-95 antibodies (red). $\boldsymbol{B}$, Neurons expressing SAP97-EGFP constructs before (left) and after (right) perfusion with 0.5\% Triton X-100. Bar graph depicts average fluorescence intensity ratios (after Triton/before) of synaptic $\alpha$-, $\beta$-, and $\Delta$ SAP97-EGFP puncta (mean \pm SEM; $n \geq 4$ from two separate experiments). C, Neurons expressing $\alpha-, \beta$-, or $\triangle$ SAP97-EGFP under control conditions (left) or $5 \mathrm{~h}$ treatment with 10 $\mu \mathrm{M}$ latrunculin (right). Bar graph depicts average SAP97-EGFP intensity in untreated (- bars; normalized to 1, \pm SEM) and latrunculin-treated ( + bars) neurons ( $n \geq 8$ fields of view from 2 separate experiments). $\boldsymbol{D}$, EM micrographs depicting unlabeled (left) and immunogold-labeled synapses from neurons expressing $\alpha$ - and $\beta$ SAP97-EGFP (center and right, respectively). $\alpha$ SAP97 was typically observed at the PSD (white arrowheads denote PSD; black arrows denote immunogold labeling), whereas $\beta S A P 97$ was generally in non-PSD regions of spines, often in close proximity to the plasma membrane (also see supplemental Fig. in transfected neurons expressing $\alpha$ - or BSAP97-EGFP. Here, we found that both isoforms significantly increased the accumulation of surface GluR1 on spines compared with untransfected cells or those expressing $\Delta$ SAP97 (Fig. $5 A, B$ ). Furthermore, ratios of cell-surface to total GluR1 at spines were similar for both isoforms ( $\alpha$ SAP97 ratio, $0.66 \pm 0.05$; $\beta$ SAP97 ratio, $0.70 \pm 0.03)$, suggesting that neither SAP97 isoform increased the intracellular retention of AMPARs within spine heads. No such increases in spine accumulation were observed for the GluR3 subunit of AMPARs, indicating that $\alpha$ - and $\beta$ SAP97EGFP specifically influence the localization of GluR1 (supplemental Results; supplemental Fig. S5C, available at www. jneurosci.org as supplemental material).

This data show that both $\alpha$ - and $\beta$ SAP97 can recruit GluR1 to the postsynaptic plasma membrane. However, it is unclear whether these isoforms act by chaperoning GluR1-containing receptors into and out of spines or by providing docking sites at the postsynaptic plasma membrane. To address this question, we examined the dynamic properties of GluR1 in the presence of $\alpha$ - and $\beta$ SAP97. Neurons were cotransfected with recombinant GluR1 tagged at its $\mathrm{N}$ terminus with monomeric Cherry (mCh-GluR1) and either soluble EGFP or $\alpha-, \beta-$, or $\Delta$ SAP97EGFP using calcium phosphate precipitation. Compared with lentivirus infection, this approach did not significantly alter the localization or exchange kinetics of SAP97-EGFP isoforms (supplemental Fig. S6A; supplemental Table S1, available at www.jneurosci.org as supplemental material) yet provided an efficient means of coexpressing SAP97-EGFP and mCh-GluR1 for live imaging. Like endogenous GluR1, mCh-GluR1 exhibited a diffuse somatodendritic pattern with little enrichment in dendritic spines when expressed alone or in combination with EGFP or $\triangle$ SAP97EGFP (Fig. 5C). However, when coexpressed with $\alpha$ - or $\beta$ SAP97, mCh-GluR1 acquired a punctate, synaptic distribution, indicating its recruitment to spines (Fig. $5 C, D)$. These data suggested that $\mathrm{mCh}-$ GluR1 behaved similarly to its endogenous counterpart with respect to SAP97mediated localization. To confirm that synaptically recruited mCh-GluR1 was

$\leftarrow$

S4, available at www.jneurosci.org as supplemental material). $\boldsymbol{E}$, Quantification of immunogold labeling of $\alpha$ - and $\beta S A P 97-E G F P$ at the PSD ( $<50 \mathrm{~nm}$ distance) and in non-PSD regions $(50-700 \mathrm{~nm})$. 
A

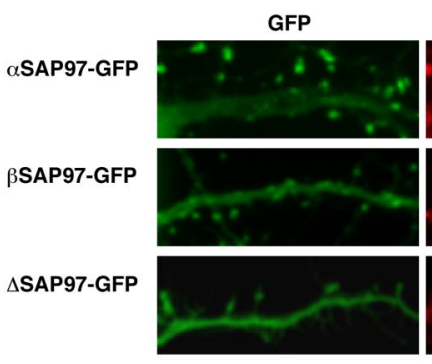

C
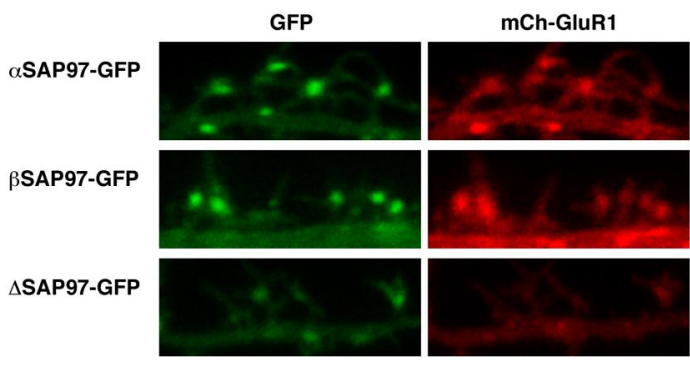

E

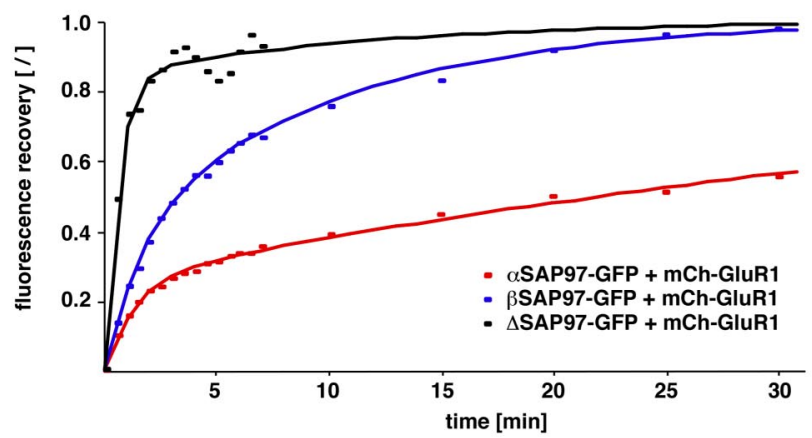

G

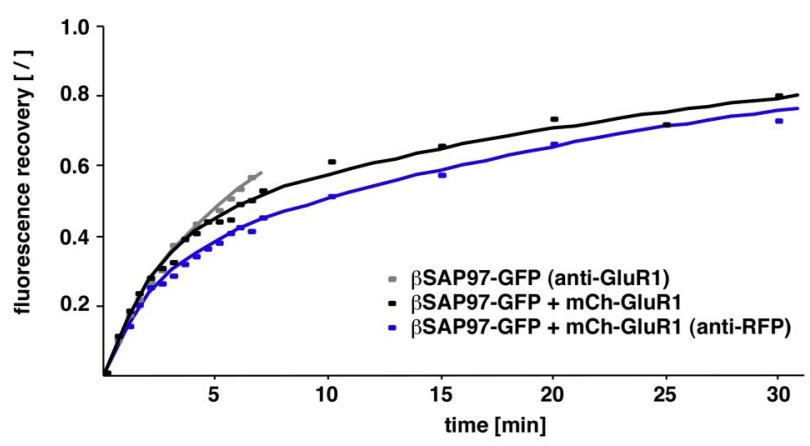

endogenous GluR1
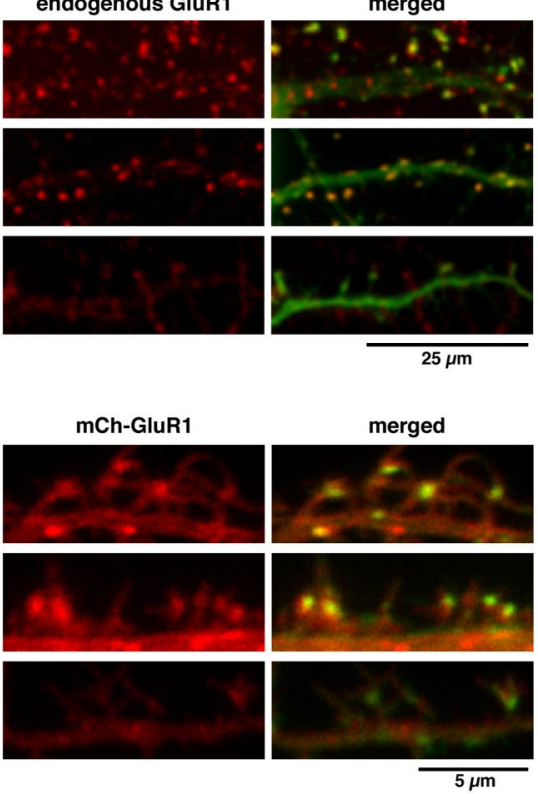

B
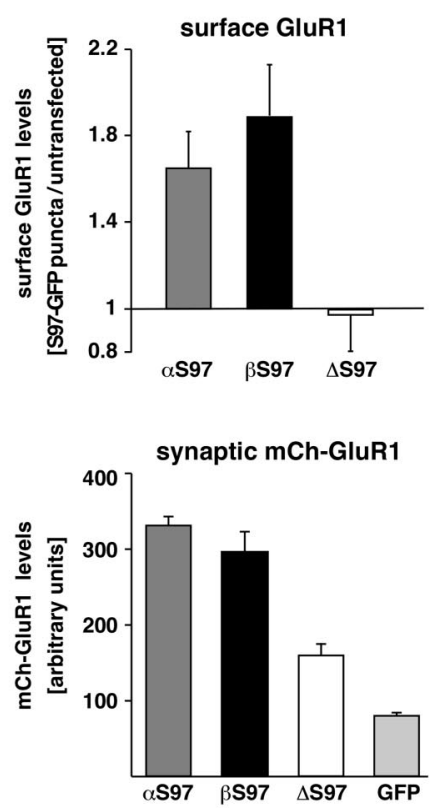

$\mathbf{F}$

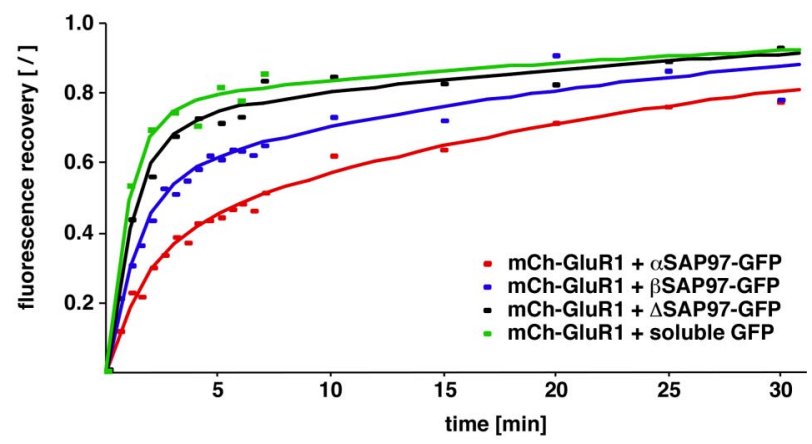

H

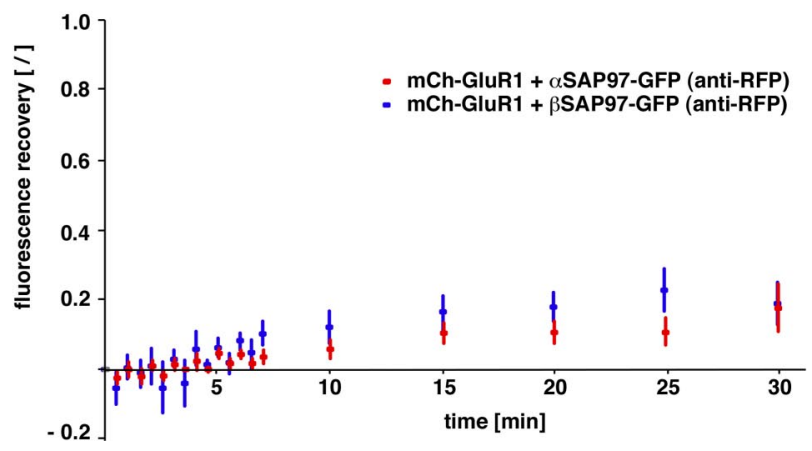

Figure 5. SAP97 isoform-specific regulation of GluR1 exchange kinetics. $\boldsymbol{A}$, Dendrites of neurons transfected with $\alpha-$, $\beta-$, or $\Delta$ SAP97-EGFP (green; left) and stained with antibodies against endogenous cell-surface GluR1 (red; middle). $\boldsymbol{B}$, Surface GluR1 levels at SAP97-EGFP puncta relative to the GluR1 intensity in untransfected neurons from the same fields of view (left bar graph; means \pm SEM; $n \geq 5$ cells for each condition). C, High-magnification images of dendritic spines from neurons cotransfected with mCh-GluR1 (red; middle) and $\alpha$-, $\beta$-, or $\Delta$ SAP97-EGFP (green; left). $\boldsymbol{D}, \mathrm{mCh}-$ GluR1 fluorescence intensity at SAP97-EGFP puncta or spines expressing soluble EGFP (left bar graph; means \pm SEM; $n \geq 48$ puncta from 6 neurons). $\boldsymbol{E}$, FRAP curves for $\alpha$ - (red), $\beta$ (blue), and $\triangle$ SAP97-EGFP puncta (black) in neurons cotransfected with $m C h-G l u R 1$ ( $n \geq 12$ puncta from $\geq 6$ cells). $\boldsymbol{F}$, Fluorescence recovery of mCh-GluR1 puncta in neurons cotransfected with soluble EGFP (green), $\alpha$-(red), $\beta$-(blue), or $\Delta$ SAP97-EGFP (black; $n \geq 12$ puncta from $\geq 6$ cells per construct). G, FRAP of $\beta S A P 97-E G F P$ puncta coexpressing mCh-GluR1 under control conditions (black), after crosslinking with anti-RFP antibody (blue) or after crosslinking of endogenous surface GluR1 (gray; $n \geq 10$ puncta from $\geq 7$ cells per condition). $\boldsymbol{H}$, FRAP of mCh-GluR1 puncta after crosslinking of surface GluR1 on neurons expressing $\alpha$ - (red; $n=8$ puncta from 4 cells) or $\beta$ SAP97-EGFP puncta (blue; $n=10$ puncta from 5 cells).

also localized to the plasma membrane, we labeled surface mChGluR1 using anti-RFP antibodies (which recognize this spectral variant of RFP). Quantification of cell-surface versus total mChGluR1 in individual dendritic spines expressing $\alpha$ - and $\beta$ SAP97 revealed that, similar to endogenous GluR1, the ratios of surface to total protein were nearly identical for both constructs ( $\alpha$ SAP97 fluorescence intensity ratio, $1.54 \pm 0.27$; $\beta$ SAP97 ratio, $1.67 \pm 0.30)$.
We next used FRAP to examine the dynamic properties of mCh-GluR1 in the presence of soluble EGFP or $\alpha-, \beta$-, or $\Delta$ SAP97-EGFP. In these experiments, mCh-GluR1 puncta in dendritic spines were bleached with a $514 \mathrm{~nm}$ laser line and the same puncta subsequently bleached at $488 \mathrm{~nm}$ to monitor recovery of the SAP97-EGFP fluorescence. As expected, the exchange rates of $\alpha-, \beta-$, or $\Delta$ SAP97-EGFP in cotransfected neurons were 
very similar to those in lentivirus-infected neurons (Fig. 5E; compare with Figs. $2 B$, $3 D$ and supplemental Table $S 1$, available at www.jneurosci.org as supplemental material). In contrast, mCh-GluR1 fluorescence recovery was clearly influenced by coexpression with $\alpha$ - and $\beta$ SAP97 isoforms (Fig. 5F, Table 1). We found that $\alpha$ SAP97 had the most profound effect on GluR1 recovery, with $<50 \%$ of $\mathrm{mCh}-$ GluR1 fluorescence regained within the first $5 \mathrm{~min}$, compared with $\sim 70 \%$ in $\Delta$ SAP97-EGFP-transfected neurons and $\sim 80 \%$ in neurons expressing soluble EGFP (supplemental Table S1, available at www.jneurosci.org as supplemental material). $\beta$ SAP97 had an intermediate effect, with $\sim 60 \%$ recovery of $\mathrm{mCh}-\mathrm{GluR} 1$ fluorescence within the first $5 \mathrm{~min}$ (supplementalTableS1, availableatwww.jneurosci. org as supplemental material). Curve fitting revealed that although $\alpha-, \beta$-, or $\triangle$ SAP97-EGFP altered the fractional amounts of mCh-GluR1 in the fast and slow pools ( $a$ and $1-a$, respectively), they did not significantly change the rates of exchange $\left(\tau_{1}\right.$ and $\left.\tau_{2}\right)$ (Table 1$)$. Thus, although $\alpha$ - and $\beta$ SAP97 appear to create additional docking sites for GluR1, the lack of concordance between the corresponding curves for $\alpha$-, $\beta$-, or $\Delta$ SAP97EGFP recovery and those for $\mathrm{mCh}-\mathrm{GluR} 1$ (compare Fig. 5E, F) indicate that these receptors do not transit in a complex with SAP97 isoforms.

Our data suggest that $\alpha$ - and $\beta$ SAP97 can tether cell-surface GluR1 within dendritic spines. However, we could not distinguish between cell-surface and internal mCh-GluR1 during FRAP experiments. To examine whether the fluorescence recovery of mCh-GluR1 in the presence of SAP97 isoforms could be attributed to lateral diffusion of surface receptors in the plasma membrane, we used an antibody cross-linking assay designed to immobilize surface receptors without influencing the properties of intracellular pools (Ashby et al., 2006; Bats et al., 2007). Neurons cotransfected with $\alpha$ - or $\beta$ SAP97-EGFP and mCh-GluR1 were preincubated sequentially with polyclonal rabbit anti-RFP and anti-rabbit secondary antibodies, to crosslink surface mCh-GluR1 before FRAP experiments. This treatment had no effect on SAP97 exchange, as assessed by 3 SAP97EGFP recovery after either endogenous or mCh-GluR1 crosslinking with GluR1 or RFP antibodies, respectively (Fig. 5G). However, cross-linking essentially abolished the exchange of $\mathrm{mCh}-\mathrm{GluR} 1$ in the presence of both SAP97 isoforms (Fig. $5 \mathrm{H}$; supplemental Fig. S6 B, available at www.jneurosci.org as supplemental material). Although we cannot rule out the possibility that this procedure affects other aspects of GluR1 exchange such as exo/endocytosis rates, it does provide an indication that the

D
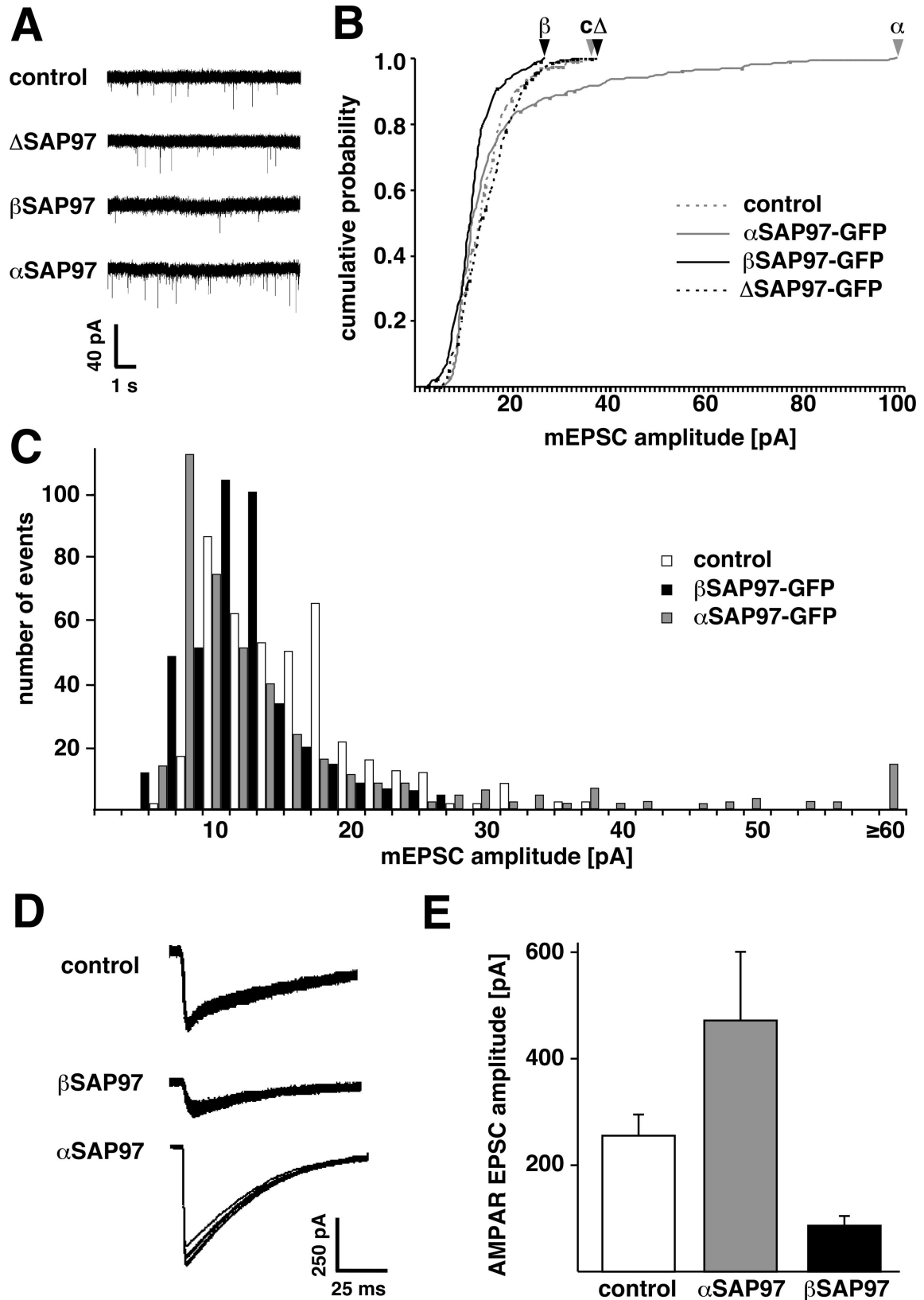

E

Figure 6. SAP97 isoform-specific effects on miniature and evoked AMPAR currents. $A$, Sample miniature EPSC traces recorded from primary hippocampal neurons transfected with soluble EGFP (control) or $\alpha-, \beta-$, or $\Delta$ SAP97-EGFP. $B$, Cumulative probability plot of mEPSC amplitudes from these neurons. The Kolmogorov-Smirnov test determined a significant effect of $\alpha$ - and BSAP97-EGFP ( $p<0.001$ ) but not $\triangle$ SAP97-EGFP on mEPSC amplitudes. Arrowheads indicate the maximum mEPSC amplitudes. $C$, Histogram depicting the same mEPSC amplitude data (400 mEPSC events per construct). Note the right shift of the histogram for neurons expressing $\alpha$ SAP97-EGFP and the left shift for those expressing $\beta S A P 97-E G F P . D$, Evoked EPSC sample traces from postsynaptic neurons transfected with $\alpha$ - and $\beta$ SAP97-EGFP and untransfected controls (10 superimposed sweeps per condition). $\boldsymbol{E}$, Quantification of AMPAR EPSC amplitudes (means \pm SEM; $n \geq 10$ paired recordings).

observed fluorescence recovery is attributable to lateral diffusion of cell-surface receptors. Moreover, these cross-linking experiments provide further evidence that SAP97 and GluR1 do not transit as a complex within spines, as virtually eliminating the mobility of GluR1 had no affect on SAP97 dynamics.

\section{SAP97 isoform-specific regulation of miniature and evoked AMPAR EPSCs}

We next examined whether, in line with their effects on GluR1 localization and dynamics, $\alpha$ - and $\beta$ SAP97 also influenced AMPAR function in dissociated hippocampal neurons. To this 
end, miniature AMPAR mEPSCs were recorded from neurons transfected with $\alpha-, \beta$-, or $\triangle$ SAP97-EGFP constructs or with soluble EGFP for control (Fig. 6A-C; supplemental Table S2, available at www.jneurosci.org as supplemental material). As expected, soluble EGFP had no effect on mEPSC amplitude or frequency compared with untransfected cells (data not shown). Similarly, overexpression of $\triangle$ SAP97-EGFP did not change mEPSC amplitude or frequency compared with the control condition (Fig. $6 A, B$ ) (control amplitude: $15.3 \pm 0.27 \mathrm{pA}$, frequency: $1.20 \pm 0.25 \mathrm{~Hz}, n=6 ; \Delta$ SAP97 amplitude: $16.0 \pm 0.34 \mathrm{pA}$, frequency: $1.23 \pm 0.54 \mathrm{~Hz}, n=8$ ). However, expression of $\alpha$ SAP97-EGFP significantly increased mEPSC amplitude above control levels (18.4 $\pm 0.7 \mathrm{pA} ; n=5)$, whereas, unexpectedly, $\beta S A P 97-E G F P$ significantly decreased the mEPSC amplitude $(13.7 \pm 0.17 \mathrm{pA} ; n=7)$.

To confirm this surprising result, we examined the effects of $\alpha$ - and $\beta$ SAP97 on synaptically evoked AMPAR-mediated EPSCs (Fig. 6D,E; supplemental Table S2, available at www.jneurosci. org as supplemental material). Paired whole-cell recordings were performed between pyramidal neurons in dissociated hippocampal cultures, with the postsynaptic cell expressing soluble EGFP, $\alpha$-, or $\beta$ SAP97-EGFP. Consistent with our mEPSC analysis, we found that the amplitudes of evoked EPSCs were significantly increased in pyramidal neurons expressing $\alpha$ SAP97-EGFP relative to uninfected controls ( $472 \pm 128 \mathrm{pA}, n=13$ paired recordings; control: $256 \pm 40 \mathrm{pA}, n=23$ paired recordings, $p<0.05)$ and significantly decreased in those expressing $\beta$ SAP97-EGFP $(87 \pm 17 \mathrm{pA}$, $n=10 ; p<0.01)$. These data demonstrate that $\alpha$ SAP97-EGFP increases the number of functional AMPARs within the PSD, as reported previously (Rumbaugh et al., 2003; Schlüter et al., 2006), whereas $\beta$ SAP97-EGFP unexpectedly decreases this number.

In a previous study, we showed that postsynaptic $\beta$ SAP97 overexpression could increase the size of adjacent presynaptic boutons via transsynaptic signaling (Regalado et al., 2006). It thus seemed possible that the observed electrophysiological phenotypes could be caused by differential effects of $\alpha$ - and $\beta$ SAP97 on presynaptic size and/or function. However, we found these isoforms to have identical effects on juxtaposed presynaptic boutons, with both $\alpha$ - and $\beta$ SAP97-EGFP significantly increasing the size of the total recycling pool of synaptic vesicles as assessed by FM4-64 uptake (see supplemental Results; supplemental Fig. S8, available at www.jneurosci.org as supplemental material). Furthermore, neither isoform altered the synaptic vesicle exocytosis kinetics at juxtaposed boutons, as measured by FM4-64 destaining rates (supplemental Fig. S8, available at www. jneurosci.org as supplemental material). These data indicate that transsynaptic effects cannot account for the dramatic differences in AMPAR EPSC amplitudes seen in neurons expressing $\alpha$ - or BSAP97.

Another mechanism that could explain our findings is that $\beta$ SAP97, through its binding to GluR1, holds AMPARs in an extrasynaptic domain of the plasma membrane, preventing their access to the PSD and presynaptically released glutamate. The non-PSD, perisynaptic localization of $\beta S A P 97$ observed in this and other studies is consistent with this idea. To explore this possibility, we examined the ability of $\beta$ SAP97 to rescue the phenotype produced by knockdown of PSD-95, i.e., the loss of AMPAR-mediated miniature EPSCs. We reasoned that BSAP97 may localize to extrasynaptic sites because it lacks a palmitoylation domain and cannot compete with PSD-95 for binding sites within the PSD. However, in the absence of PSD-95, binding sites may become available within the PSD, enabling $\beta S A P 97$ to enter this compartment, recruit GluR1-containing AMPARs, and thus rescue the PSD-95 knockdown phenotype. In line with this model, a recent study conducted in hippocampal organotypic slices showed that $\beta$ SAP97 overexpression was able to rescue the loss of AMPAR-mediated EPSCs in neurons lacking PSD-95, although $\beta$ SAP97 overexpression in the presence of PSD-95 had no effect on AMPAR EPSCs (Schlüter et al., 2006).

Utilizing constructs that simultaneously express EGFP-tagged $\alpha$ or BSAP97 together with a short hairpin RNA to knock down PSD-95 expression (sh95) (Rumbaugh et al., 2003; Schlüter et al., 2006), we first verified that PSD-95 levels were effectively lowered in dissociated hippocampal cultures. We found that these constructs were highly effective at reducing PSD-95 in neurons whether introduced by lentivirus (Fig. $7 A, B$ ) or calcium phosphate transfection (data not shown). Moreover, the knockdown had no obvious effects on the expression level, localization, or dynamic properties of coexpressed $\alpha$ - or $\beta$ SAP97 (Fig. $7 B, C$; see also supplemental Fig. S7, available at www.jneurosci.org as supplemental material). Finally, we examined whether synaptic $\alpha$ - and $\beta$ SAP97 were still able to promote the cell-surface accumulation of GluR1 in the absence of PSD-95. Surface immunostaining for GluR1 revealed that this function was intact for both isoforms (Fig. 7C,D).

We next examined the ability of $\alpha$ - and $\beta$ SAP97 to rescue the loss of AMPAR-mediated mEPSCs caused by PSD-95 knockdown. Miniature EPSCs were recorded from neurons transfected with constructs expressing sh95 with soluble EGFP, or sh95 with EGFP-tagged $\alpha$ - or $\beta$ SAP97. As reported previously (Rumbaugh et al., 2003; Schlüter et al., 2006), expression of sh95 alone caused a near-complete loss of AMPAR-mediated currents (Fig. 7E), reflected by a dramatic reduction in mEPSC frequency (Fig. 7F) (control frequency: $1.54 \pm 0.37 \mathrm{~Hz}, n=32$; sh95 frequency: $0.13 \pm 0.11 \mathrm{~Hz}, n=14, p<0.001)$. This phenotype was rescued by $\alpha$ SAP97 expression, which restored mEPSC frequency to control levels $(1.15 \pm 0.42 \mathrm{~Hz} ; n=12)$ but not by $\beta$ SAP97 expression $(0.06 \pm 0.03 \mathrm{~Hz} ; n=18 ; p<0.001)$ (Fig. $7 E, F)$.

One explanation for this striking result is that $\beta$ SAP97 does not localize to the PSD, even in the absence of PSD-95, but instead sequesters AMPARs in an extrasynaptic domain where the receptors cannot support synaptic transmission. An alternative is that $\beta$ SAP97 impedes the channel conductance of AMPARs and thus dramatically decreases AMPAR-mediated currents. To distinguish between these possibilities, we measured the peak amplitude of AMPAR currents elicited in $\alpha$ - and $\beta$ SAP97-EGFPtransfected neurons by focal application of exogenous AMPA, which activates both synaptic and extrasynaptic AMPARs. The presence of inward AMPAR currents in $\beta$ SAP97-transfected neurons would support the former possibility (i.e., extrasynaptic AMPAR sequestration), whereas an absence of such currents would support the latter one (i.e., impaired channel conductance). Intriguingly, we found that the peak amplitude of AMPAinduced currents in $\beta$ SAP97-expressing neurons was significantly higher than that seen in $\alpha$ SAP97-expressing neurons ( $\beta$ SAP97: $-232.3 \pm 32.6 \mathrm{pA}, n=9$; $\alpha$ SAP97: $-116.31 \pm 12.8 \mathrm{pA}$, $n=9, p<0.005, t$ test) (Fig. $7 G$ ). Together with the previous electrophysiology results, this finding indicates that neurons expressing $\beta$ SAP97 have greater total numbers of cell-surface AMPARs, but significantly fewer receptors positioned beneath neurotransmitter release sites, a concept consistent with the ability of $\beta$ SAP97 to retain surface AMPARs in an extrasynaptic/nonPSD compartment (Fig. 8).

\section{Discussion}

We have demonstrated the ability of two synaptic SAP97 isoforms to directly regulate the localization and dynamics of 

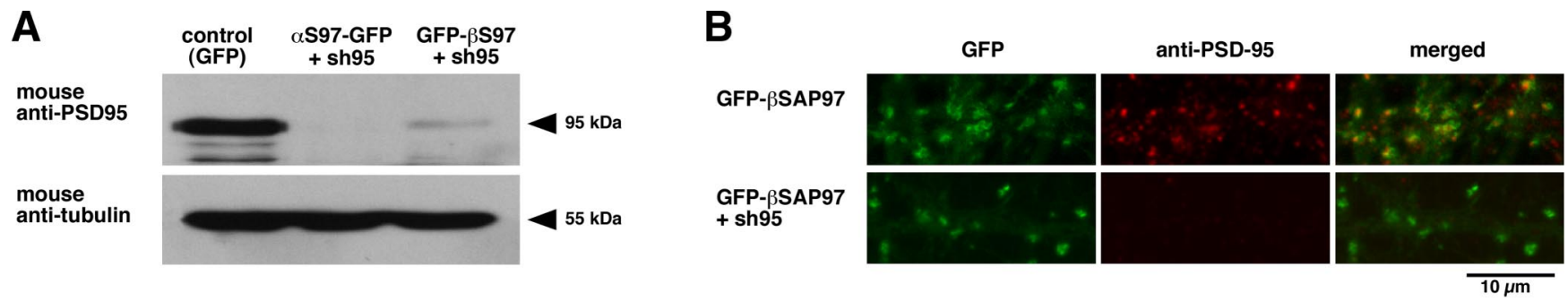

\section{C aSAP97-GFP

aSAP97-GFP
+ sh95

GFP-BSAP97

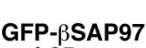
$+\operatorname{sh} 95$
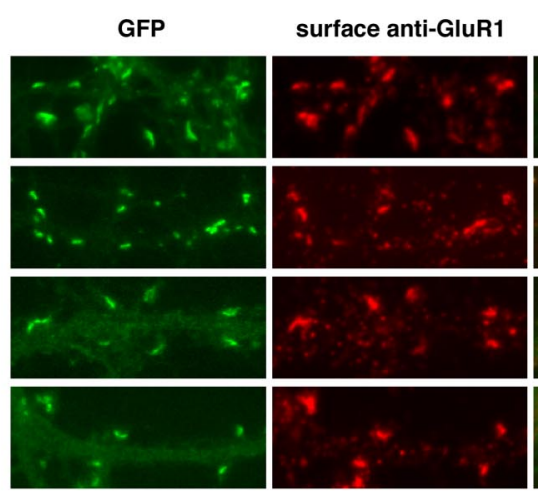

E
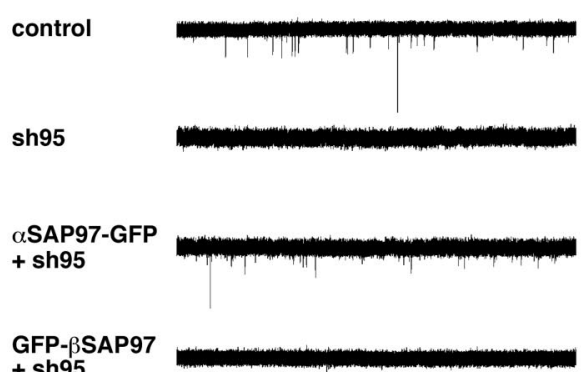

$+\operatorname{sh} 95$

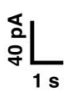

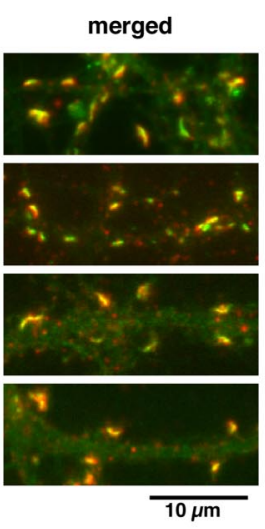

D

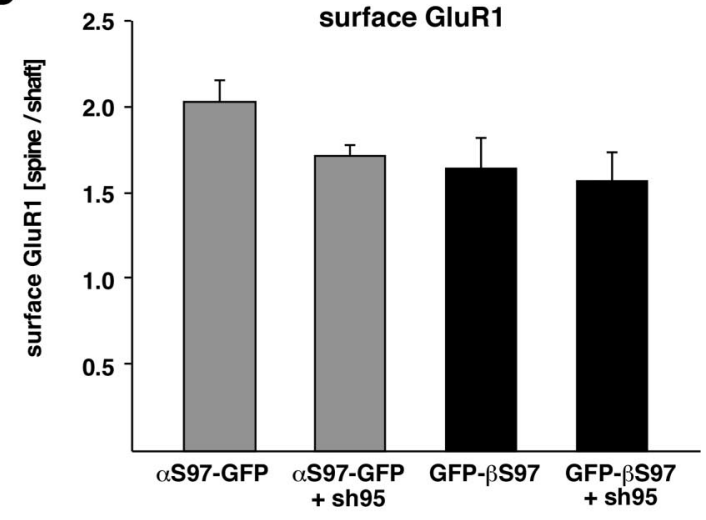

G

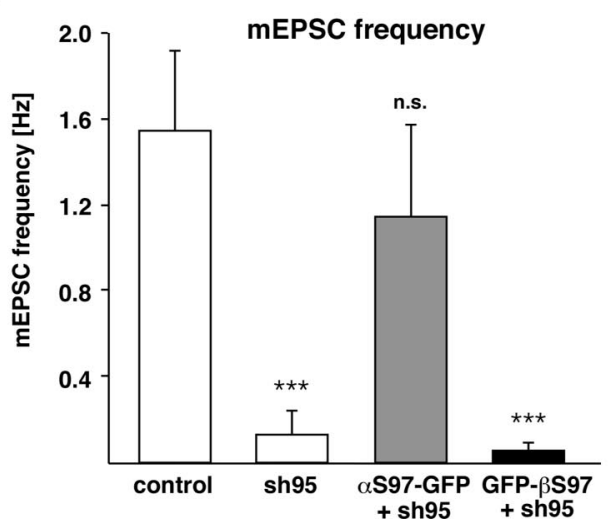

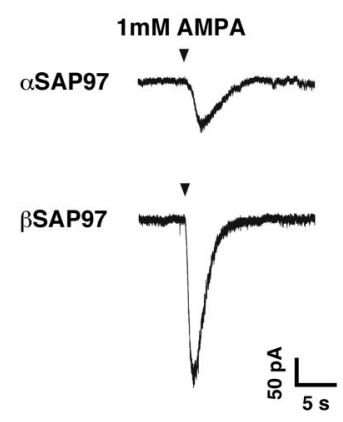

Figure 7. Isoform-specific rescue of PSD-95 knockdown phenotype. A, Western blot of lysates from dissociated hippocampal neurons infected with lentivirus expressing soluble EGFP for control (left lane), $\alpha$ SAP97-EGFP plus sh95 (middle lane), or EGFP- $\beta$ SAP97 plus sh95 (right lane) and immunostained with antibodies against PSD-95 (top) or $\alpha$-tubulin (bottom). Note the dramatic reduction of PSD-95 in neurons expressing the sh95 RNAi. $\boldsymbol{B}$, Dendrites of neurons infected with EGFP- $\beta$ SAP97 \pm sh95 (green; left) and immunostained with PSD-95 antibodies (red; middle). Merged images (right) show that PSD-95 immunoreactivity colocalizes with $\beta$ SAP97 in dendritic spines of control neurons (top) but is absent from neurons expressing sh95 (bottom). C, Dendrites of neurons infected with $\alpha$ SAP97-EGFP \pm sh95 (top) or EGFP- $\beta$ SAP97 \pm sh95 (bottom) and immunostained with antibodies to label surface GluR1 (red). D, Quantification of surface GluR1 intensity (expressed as spine/shaft ratio \pm SEM) in neurons infected with $\alpha$ SAP97-EGFP or EGFP- $\beta$ SAP97 with or without sh95. Expression of sh95 does not significantly alter surface GluR1 levels in the presence of either SAP97 isoform. E, Sample mEPSC traces from untransfected control neurons (top) and those coexpressing sh95 together with soluble EGFP (sh95), $\alpha$ SAP97-EGFP, or EGFP- $\beta$ SAP97.F, Quantification of mEPSC frequency data from these cells. The Mann-Whitney Rank sum test determined a significant effect $(p<0.001)$ of sh95 and EGFP- $\beta$ SAP97 plus sh95 but not $\alpha$ SAP97-EGFP plus sh95, on mini-EPSC frequency. G, Sample traces of inward AMPAR currents induced by focal AMPA application in $\alpha$ - (top) or $\beta$ SAP97-EGFP (bottom)-transfected neurons.

GluR1-containing AMPARs within spines. The $\alpha$ - and $\beta$ SAP97 isoforms used in this study share a common I3/I5 insert but have alternatively spliced $\mathrm{N}$ termini and distinct postsynaptic localizations and kinetic profiles. Furthermore, both isoforms alter the subsynaptic localization of GluR1 within dendritic spines and in so doing influence the responsiveness of excitatory synapses to glutamate.

\section{Role of $\alpha$ SAP97 in the synaptic localization of AMPARs}

The expression of $\alpha$ SAP97 (Schlüter et al., 2006) in mouse and human brain is confirmed by the presence of cDNA sequences in expressed sequence tag databases (GenBank accession numbers:
DA121908, BY131151, BY124397). Intriguingly, $\alpha$ SAP97 shares nearly identical N-terminal sequences with PSD-95 and PSD-93 and has correspondingly similar features: palmitoylation of $\mathrm{N}$-terminal cysteines, PSD localization, and slow exchange kinetics (Craven et al., 1999; Okabe et al., 1999; El-Husseini et al., 2000; Firestein et al., 2000; Kuriu et al., 2006). Thus, $\alpha$ SAP97 appears to be a stable component of the PSD.

Multiple protein and lipid interactions likely contribute to the association of $\alpha$ SAP97 with the PSD. In particular, our experiments suggest a crucial role for palmitoylation in targeting and anchoring $\alpha$ SAP97 to the PSD. Exactly how this lipid moiety anchors SAP97 within the PSD is unclear, but presumably, it 

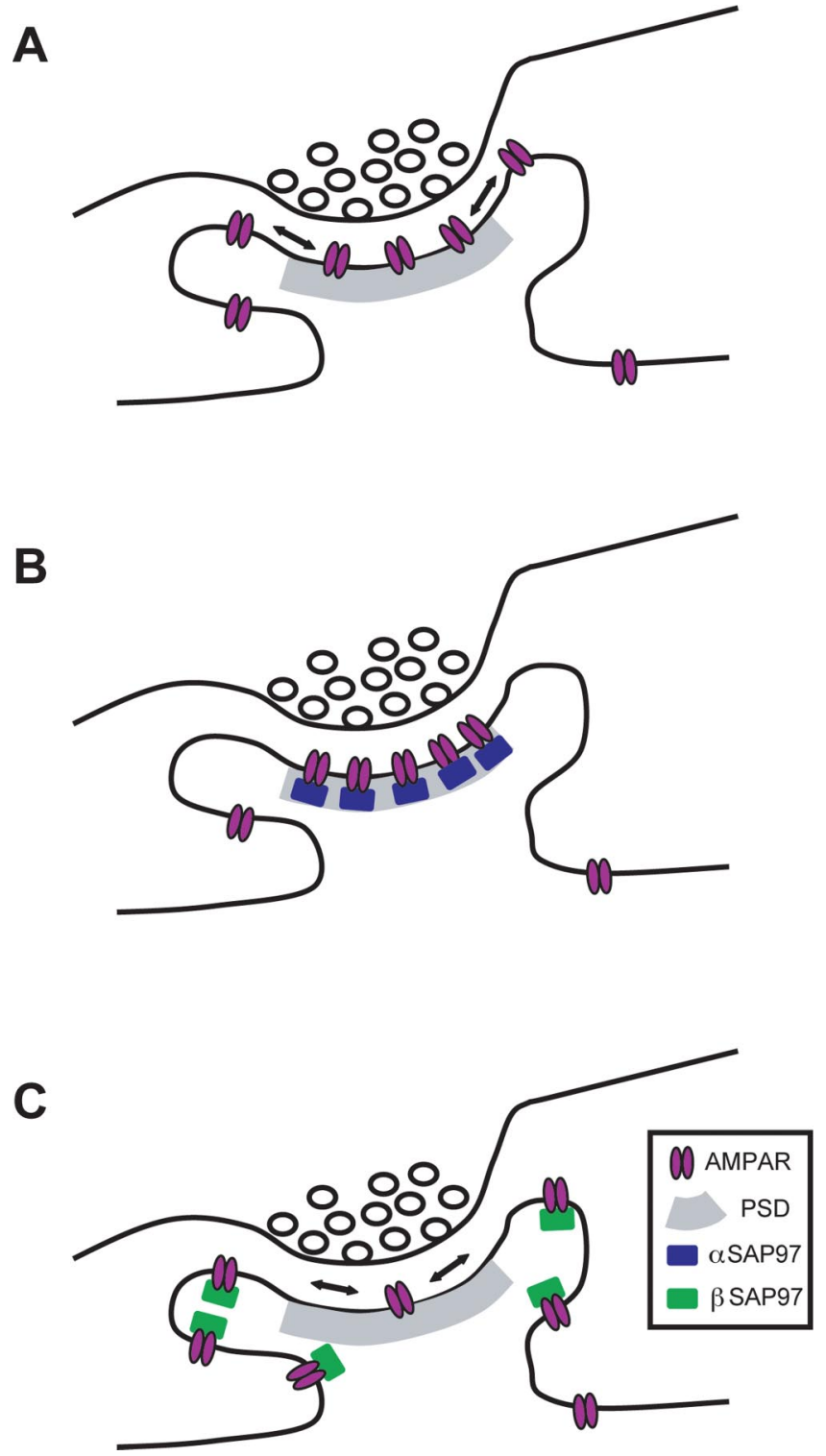

Figure 8. Model of how $\alpha$ - and $\beta$ SAP97 regulate the subsynaptic localization of GluR1containing AMPARs. $\boldsymbol{A}$, Schematic diagram of an excitatory synapse at steady state. Cell-surface AMPARs are concentrated at the PSD through their interactions with PSD-95 but can laterally diffuse to extrasynaptic domains of the spine. $\boldsymbol{B}$, Excitatory synapse expressing high levels of $\alpha$ SAP97. This is oform localizes to the PSD, creating additional binding sites for surface AMPARs within this domain and restricting their lateral mobility. C, Excitatory synapse expressing high levels of $\beta$ SAP97. This isoform localizes to extrasynaptic domains of the spine, creating new non-PSD binding sites for surface AMPARs and thereby inhibiting their diffusion into the PSD.

tethers the protein to specialized lipid domains, restricting its lateral mobility and possibly facilitating other protein interactions within this structure (Hering and Sheng, 2003). Similar findings with a palmitoylated form of GRIP/ABP1 are consistent with a central role of cholesterol lipids in the synaptic targeting of proteins to the PSD (Osten et al., 2000; deSouza and Ziff, 2002; Hering and Sheng, 2003).

We also examined the impact of $\alpha$ SAP97 on the spatial distribution and function of GluR1-containing AMPARs. Our data show that $\alpha$ SAP97 overexpression significantly increases the surface expression of synaptic GluR1, as well as miniature and evoked AMPAR-mediated currents, indicating that $\alpha$ SAP97, like PSD-95, recruits GluR1-containing AMPARs into the PSD (Schnell et al., 2002; Bats et al., 2007). Furthermore, $\alpha$ SAP97 rescued the loss of AMPAR-mediated EPSCs caused by PSD-95 knockdown in dissociated hippocampal neurons, a behavior also observed in organotypic slices (Schlüter et al., 2006). These findings point to a significant functional redundancy between $\alpha$ SAP97 and PSD-95. One notable difference is that the former interacts directly with GluR1 (Cai et al., 2002), whereas the latter interacts with AMPAR subunits via a transmembrane AMPAR regulatory protein (TARP)-dependent mechanism (Tomita et al., 2003, 2004; Nicoll et al., 2006; Ziff, 2007). Additional experiments are needed to investigate the functional relevance of these interactions, which could relate to a more fundamental role of PSD-95 in maintaining synaptic pools of GluR2/3, although this has not been clearly established (Boehm et al., 2006; Ehrlich et al., 2007).

\section{Role of $\beta$ SAP97 in the synaptic localization of AMPARs}

BSAP97 is located in a distinct subsynaptic domain from $\alpha$ SAP97, as demonstrated by FRAP, Triton, and latrunculin experiments and light- and EM-level immunostaining. We found that a majority of $\beta$ SAP97 in dendritic spines is associated with non-PSD structures at the plasma membrane and within the spine head, in line with previous findings (Aoki et al., 2001; DeGiorgis et al., 2006). These structures may represent the cortical actin/spectrin cytoskeleton, consistent with $\beta$ SAP97's sensitivity to Triton and latrunculin and its ability to bind the cortical cytoskeletal protein 4.1 (Lue et al., 1994; Rumbaugh et al., 2003).

How does the L27 domain confer a non-PSD yet postsynaptic distribution on $\beta$ SAP97? Studies in non-neuronal cells suggest that the L27 sequence directs $\beta S A P 97$ to the cortical cytoskeleton through an interaction with CASK (Wu et al., 1998; Lee et al., 2002). In neurons, CASK is believed to localize to the plasma membrane of dendritic spines via an association with the celladhesion protein syndecan (Hsueh et al., 1998), providing a putative link between $\beta$ SAP97 and the spine plasma membrane. Importantly, the L27 domain has also been suggested to facilitate homo-oligomerization of $\beta$ SAP97 (Nakagawa et al., 2004). Mutations within this domain increase the exchange of $\beta$ SAP97 within spines and fail to promote the postsynaptic localization of AMPARs (Nakagawa et al., 2004), analogous to our experiments with $\triangle$ SAP97. Together, these data indicate that the L27 domain is essential for stably anchoring $\beta$ SAP97 to the synaptic cortical cytoskeleton and recruiting AMPARs to the plasma membrane.

We also examined whether $\beta$ SAP97 regulates the synaptic localization and function of GluR1-containing AMPARs. As with $\alpha$ SAP97, overexpression of $\beta$ SAP97 increased the surface expression of endogenous and recombinant GluR1 within dendritic spines. Unexpectedly, we observed a marked decrease in AMPAR-mediated synaptic transmission in these neurons that was consistent for both miniature and evoked currents. Furthermore, $\beta S A P 97$ did not rescue the loss of AMPAR mEPSCs seen in neurons lacking PSD-95. A possible explanation for these data was that $\beta$ SAP97 interfered with AMPAR channel conductance. However, activation of both synaptic and extrasynaptic AMPARs via focal AMPA application revealed that peak amplitudes of AMPA-induced currents were significantly greater in neurons expressing $\beta$ SAP97 compared with $\alpha$ SAP97. These results clearly demonstrate that although $\beta$ SAP97 strongly promotes the postsynaptic, cell-surface expression of GluR1-containing AMPARs, it binds and sequesters these receptors within an extrasynaptic domain, preventing their access to synaptic glutamate (Fig. 8).

Although our data consistently demonstrate that BSAP97 overexpression reduces synaptic AMPAR-mediated currents, 
this had not been reported in previous studies, which either show an increase in EPSC amplitude (Nakagawa et al., 2004) or mEPSC frequency (Rumbaugh et al., 2003) or no change at all (Schnell et al., 2002; Ehrlich and Malinow, 2004; Schlüter et al., 2006). Furthermore, our finding that $\beta$ SAP97 does not rescue AMPARmediated currents in the absence of PSD-95 is at odds with a previous study performed in hippocampal organotypic slices (Schlüter et al., 2006). A likely explanation for these differences is that the cell-surface levels of GluR1-containing AMPARs vary widely between hippocampal preparations. In dissociated cultures, GluR1 is readily detectable on the surface of cell bodies and dendrites, at synaptic and extrasynaptic sites, under both basal and stimulated conditions (Shi et al., 1999; Adesnik et al., 2005; Bats et al., 2007; Ehlers et al., 2007; Yudowski et al., 2007). In organotypic slices, in contrast, the vast majority of GluR1 is localized intracellularly within dendritic shafts, only moving into spines during synaptic stimulation (Shi et al., 1999). Based on previous studies showing a direct interaction between BSAP97 and GluR1 but not GluR2/3 (Leonard et al., 1998; Cai et al., 2002; von Ossowski et al., 2006), one would predict that $\beta$ SAP97 affects synaptic AMPAR currents under basal conditions in dissociated cultures but not in organotypic slices. Similarly, the ability of BSAP97 to rescue the PSD-95 knockdown may depend on the subunit composition of cell-surface AMPARs in these two preparations. If the majority of surface receptors are GluR2/3, as in organotypic slices, $\beta$ SAP97 may rescue the PSD-95 knockdown phenotype via an indirect, compensatory mechanism during AMPAR trafficking, or by facilitating the synaptic retention of GluR2/3 through TARPs (Barry and Ziff, 2002; Ehrlich et al., 2007; Shepherd and Huganir, 2007; Ziff, 2007), although this functionality of $\beta$ SAP97 has not been explored. However, if the majority of cell-surface receptors contain GluR1, as in dissociated cultures, $\beta$ SAP97 will sequester these receptors in an extrasynaptic domain and thus fail to rescue the PSD-95 knockdown phenotype.

\section{$\alpha$ - and $\beta$ SAP97 create docking sites for AMPARs within postsynaptic compartments}

In this study, we have compared the effects of two SAP97 isoforms on the synaptic localization and dynamics of the AMPAR subunit GluR1. Our results show that in cultured neurons, $\alpha$ - and BSAP97 promote the postsynaptic surface accumulation of GluR1. Both isoforms also significantly decrease GluR1 exchange, with $\alpha$ SAP97 having the more dramatic effect, consistent with its slower exchange kinetics. Importantly, both isoforms slow GluR1 exchange by increasing the fraction of tightly bound $\mathrm{mCh}-\mathrm{GluR} 1$ rather than altering the rate constants of $\mathrm{mCh}-$ GluR1 exchange (Table 1). Together with our data demonstrating that $\beta$ SAP97-EGFP exchange rates are not altered by GluR1 cross-linking, these experiments indicate that $\alpha$ - and $\beta$ SAP97 do not shuttle GluR1 into and out of the spine as a complex but instead create docking sites that serve to transiently tether AMPARs in place, similar to what has been observed for PSD-95/ TARP complexes (Bats et al., 2007). Furthermore, in agreement with several recent reports (Adesnik et al., 2005; Ashby et al., 2006; Bats et al., 2007), we observed that a majority of GluR1 in dendritic spines is at the cell surface, suggesting that $\alpha$ - and $\beta$ SAP97 bind and retain these AMPAR subunits within distinct cell-surface domains.

In summary, we have developed dynamic imaging strategies to evaluate the importance of predicted protein-protein interactions. Our data indicate that synaptic isoforms of SAP97 can directly regulate the levels, dynamics, and subsynaptic localiza- tion of GluR1-containing AMPARs. Moreover, as GluR1 has been implicated in the establishment of long-term potentiation, our work raises fundamental questions about whether different SAP97 isoforms affect GluR1 dynamics during synaptic plasticity.

\section{References}

Adesnik H, Nicoll RA, England PM (2005) Photoinactivation of native AMPA receptors reveals their real-time trafficking. Neuron 48:977-985.

Allison DW, Chervin AS, Gelfand VI, Craig AM (2000) Postsynaptic scaffolds of excitatory and inhibitory synapses in hippocampal neurons: maintenance of core components independent of actin filaments and microtubules. J Neurosci 20:4545-4554.

Aoki C, Miko I, Oviedo H, Mikeladze-Dvali T, Alexandre L, Sweeney N, Bredt DS (2001) Electron microscopic immunocytochemical detection of PSD-95, PSD-93, SAP-102, and SAP-97 at postsynaptic, presynaptic, and nonsynaptic sites of adult and neonatal rat visual cortex. Synapse 40:239-257.

Ashby MC, Maier SR, Nishimune A, Henley JM (2006) Lateral diffusion drives constitutive exchange of AMPA receptors at dendritic spines and is regulated by spine morphology. J Neurosci 26:7046-7055.

Banker G, Goslin K (1998) Culturing nerve cells, Ed 2. Cambridge, MA: MIT.

Barry MF, Ziff EB (2002) Receptor trafficking and the plasticity of excitatory synapses. Curr Opin Neurobiol 12:279-286.

Bats C, Groc L, Choquet D (2007) The interaction between Stargazin and PSD-95 regulates AMPA receptor surface trafficking. Neuron 53:719-734.

Boehm J, Ehrlich I, Hsieh H, Malinow R (2006) Two mutations preventing PDZ-protein interactions of GluR1 have opposite effects on synaptic plasticity. Learn Mem 13:562-565.

Bredt DS, Nicoll RA (2003) AMPA receptor trafficking at excitatory synapses. Neuron 40:361-379.

Cai C, Coleman SK, Niemi K, Keinänen K (2002) Selective binding of synapse-associated protein 97 to GluR-A alpha-amino-5-hydroxy-3methyl-4-isoxazole propionate receptor subunit is determined by a novel sequence motif. J Biol Chem 277:31484-31490.

Craven SE, El-Husseini AE, Bredt DS (1999) Synaptic targeting of the postsynaptic density protein PSD-95 mediated by lipid and protein motifs. Neuron 22:497-509.

DeGiorgis JA, Galbraith JA, Dosemeci A, Chen X, Reese TS (2006) Distribution of the scaffolding proteins PSD-95, PSD-93, and SAP97 in isolated PSDs. Brain Cell Biol 35:239-250.

deSouza S, Ziff EB (2002) AMPA receptors do the electric slide. Sci STKE 2002:PE45.

Drisdel RC, Green WN (2004) Labeling and quantifying sites of protein palmitoylation. Biotechniques 36:276-285.

Drisdel RC, Alexander JK, Sayeed A, Green WN (2006) Assays of protein palmitoylation. Methods 40:127-134.

Ehlers MD, Heine M, Groc L, Lee MC, Choquet D (2007) Diffusional trapping of GluR1 AMPA receptors by input-specific synaptic activity. Neuron 54:447-460.

Ehrlich I, Malinow R (2004) Postsynaptic density 95 controls AMPA receptor incorporation during long-term potentiation and experience-driven synaptic plasticity. J Neurosci 24:916-927.

Ehrlich I, Klein M, Rumpel S, Malinow R (2007) PSD-95 is required for activity-driven synapse stabilization. Proc Natl Acad Sci USA 104:4176-4181.

El-Husseini AE, Craven SE, Chetkovich DM, Firestein BL, Schnell E, Aoki C, Bredt DS (2000) Dual palmitoylation of PSD-95 mediates its vesiculotubular sorting, postsynaptic targeting, and ion channel clustering. J Cell Biol 148:159-172.

Esteban JA (2007) Intracellular machinery for the transport of AMPA receptors. Br J Pharmacol 153 [Suppl 1]:S35-S43.

Firestein BL, Craven SE, Bredt DS (2000) Postsynaptic targeting of MAGUKs mediated by distinct N-terminal domains. Neuroreport 11:3479-3484.

Hering H, Sheng M (2003) Activity-dependent redistribution and essential role of cortactin in dendritic spine morphogenesis. J Neurosci 23:11759-11769.

Hsueh YP, Yang FC, Kharazia V, Naisbitt S, Cohen AR, Weinberg RJ, Sheng M (1998) Direct interaction of CASK/LIN-2 and syndecan heparan sul- 
fate proteoglycan and their overlapping distribution in neuronal synapses. J Cell Biol 142:139-151.

Karnak D, Lee S, Margolis B (2002) Identification of multiple binding partners for the amino-terminal domain of synapse-associated protein 97 . J Biol Chem 277:46730-46735.

Klöcker N, Bunn RC, Schnell E, Caruana G, Bernstein A, Nicoll RA, Bredt DS (2002) Synaptic glutamate receptor clustering in mice lacking the SH3 and GK domains of SAP97. Eur J Neurosci 16:1517-1522.

Kuriu T, Inoue A, Bito H, Sobue K, Okabe S (2006) Differential control of postsynaptic density scaffolds via actin-dependent and -independent mechanisms. J Neurosci 26:7693-7706.

Leal-Ortiz S, Waites CL, Terry-Lorenzo R, Zamorano P, Gundelfinger ED, Garner CC (2008) Piccolo modulation of Synapsinla dynamics regulates synaptic vesicle exocytosis. J Cell Biol 181:831-846.

Lee S, Fan S, Makarova O, Straight S, Margolis B (2002) A novel and conserved protein-protein interaction domain of mammalian Lin-2/CASK binds and recruits SAP97 to the lateral surface of epithelia. Mol Cell Biol 22:1778-1791.

Leonard AS, Davare MA, Horne MC, Garner CC, Hell JW (1998) SAP97 is associated with the alpha-amino-3-hydroxy-5-methylisoxazole-4propionic acid receptor GluR1 subunit. J Biol Chem 273:19518-19524.

Lois C, Hong EJ, Pease S, Brown EJ, Baltimore D (2002) Germline transmission and tissue-specific expression of transgenes delivered by lentiviral vectors. Science 295:868-872.

Lue RA, Marfatia SM, Branton D, Chishti AH (1994) Cloning and characterization of hdlg: the human homologue of the Drosophila discs large tumor suppressor binds to protein 4.1. Proc Natl Acad Sci U S A 91:9818-9822.

Malenka RC, Bear MF (2004) LTP and LTD: an embarrassment of riches. Neuron 44:5-21.

Malinow R, Malenka RC (2002) AMPA receptor trafficking and synaptic plasticity. Annu Rev Neurosci 25:103-126.

McLaughlin M, Hale R, Ellston D, Gaudet S, Lue RA, Viel A (2002) The distribution and function of alternatively spliced insertions in $\mathrm{hDlg}$. J Biol Chem 277:6406-6412.

Micheva KD, Buchanan J, Holz RW, Smith SJ (2003) Retrograde regulation of synaptic vesicle endocytosis and recycling. Nat Neurosci 6:925-932.

Montgomery JM, Madison DV (2002) State-dependent heterogeneity in synaptic depression between pyramidal cell pairs. Neuron 33:765-777.

Montgomery JM, Pavlidis P, Madison DV (2001) Pair recordings reveal allsilent synaptic connections and the postsynaptic expression of long-term potentiation. Neuron 29:691-701.

Montgomery JM, Zamorano PL, Garner CC (2004) MAGUKs in synapse assembly and function: an emerging view. Cell Mol Life Sci 61:911-929.

Mori K, Iwao K, Miyoshi Y, Nakagawara A, Kofu K, Akiyama T, Arita N, Hayakawa T, Nakamura Y (1998) Identification of brain-specific splicing variants of the hDLG1 gene and altered splicing in neuroblastoma cell lines. J Hum Genet 43:123-127.

Müller BM, Kistner U, Veh RW, Cases-Langhoff C, Becker B, Gundelfinger ED, Garner CC (1995) Molecular characterization and spatial distribution of SAP97, a novel presynaptic protein homologous to SAP90 and the Drosophila discs-large tumor suppressor protein. J Neurosci 15:2354-2366.

Nakagawa T, Futai K, Lashuel HA, Lo I, Okamoto K, Walz T, Hayashi Y, Sheng M (2004) Quaternary structure, protein dynamics, and synaptic function of SAP97 controlled by L27 domain interactions. Neuron 44:453-467.

Nicoll RA, Tomita S, Bredt DS (2006) Auxiliary subunits assist AMPA-type glutamate receptors. Science 311:1253-1256.

Okabe S, Kim HD, Miwa A, Kuriu T, Okado H (1999) Continual remodeling of postsynaptic density and its regulation by synaptic activity. Nat Neurosci 2:804-811.

Osten P, Khatri L, Perez JL, Köhr G, Giese G, Daly C, Schulz TW, Wensky A,
Lee LM, Ziff EB (2000) Mutagenesis reveals a role for ABP/GRIP binding to GluR2 in synaptic surface accumulation of the AMPA receptor. Neuron 27:313-325.

Regalado MP, Terry-Lorenzo RT, Waites CL, Garner CC, Malenka RC (2006) Transsynaptic signaling by postsynaptic synapse-associated protein 97. J Neurosci 26:2343-2357.

Reuver SM, Garner CC (1998) E-cadherin mediated cell adhesion recruits SAP97 into the cortical cytoskeleton. J Cell Sci 111:1071-1080.

Rumbaugh G, Sia GM, Garner CC, Huganir RL (2003) Synapse-associated protein-97 isoform-specific regulation of surface AMPA receptors and synaptic function in cultured neurons. J Neurosci 23:4567-4576.

Sans N, Racca C, Petralia RS, Wang YX, McCallum J, Wenthold RJ (2001) Synapse-associated protein 97 selectively associates with a subset of AMPA receptors early in their biosynthetic pathway. J Neurosci 21:7506-7516.

Schlüter OM, Xu W, Malenka RC (2006) Alternative N-terminal domains of PSD-95 and SAP97 govern activity-dependent regulation of synaptic AMPA receptor function. Neuron 51:99-111.

Schnell E, Sizemore M, Karimzadegan S, Chen L, Bredt DS, Nicoll RA (2002) Direct interactions between PSD-95 and stargazin control synaptic AMPA receptor number. Proc Natl Acad Sci U S A 99:13902-13907.

Sharma K, Fong DK, Craig AM (2006) Postsynaptic protein mobility in dendritic spines: long-term regulation by synaptic NMDA receptor activation. Mol Cell Neurosci 31:702-712.

Shepherd JD, Huganir RL (2007) The cell biology of synaptic plasticity: AMPA receptor trafficking. Annu Rev Cell Dev Biol 23:613-643.

Shi SH, Hayashi Y, Petralia RS, Zaman SH, Wenthold RJ, Svoboda K, Malinow R (1999) Rapid spine delivery and redistribution of AMPA receptors after synaptic NMDA receptor activation. Science 284:1811-1816.

Tomita S, Chen L, Kawasaki Y, Petralia RS, Wenthold RJ, Nicoll RA, Bredt DS (2003) Functional studies and distribution define a family of transmembrane AMPA receptor regulatory proteins. J Cell Biol 161:805-816.

Tomita S, Fukata M, Nicoll RA, Bredt DS (2004) Dynamic interaction of stargazin-like TARPs with cycling AMPA receptors at synapses. Science 303:1508-1511.

Topinka JR, Bredt DS (1998) N-terminal palmitoylation of PSD-95 regulates association with cell membranes and interaction with $\mathrm{K}+$ channel Kv1.4. Neuron 20:125-134.

Tsuriel S, Geva R, Zamorano P, Dresbach T, Boeckers T, Gundelfinger ED, Garner CC, Ziv NE (2006) Local sharing as a predominant determinant of synaptic matrix molecular dynamics. PLoS Biol 4:e271.

Valtschanoff JG, Burette A, Davare MA, Leonard AS, Hell JW, Weinberg RJ (2000) SAP97 concentrates at the postsynaptic density in cerebral cortex. Eur J Neurosci 12:3605-3614.

Van der Kloot W (1991) Down-regulation of quantal size at frog neuromuscular junctions: possible roles for elevated intracellular calcium and for protein kinase C. J Neurobiol 22:204-214.

von Ossowski I, Oksanen E, von Ossowski L, Cai C, Sundberg M, Goldman A, Keinänen K (2006) Crystal structure of the second PDZ domain of SAP97 in complex with a GluR-A C-terminal peptide. Febs J 273:5219-5229.

Wu H, Reuver SM, Kuhlendahl S, Chung WJ, Garner CC (1998) Subcellular targeting and cytoskeletal attachment of SAP97 to the epithelial lateral membrane. J Cell Sci 111:2365-2376.

Wu H, Nash JE, Zamorano P, Garner CC (2002) Interaction of SAP97 with minus-end-directed actin motor myosin VI. Implications for AMPA receptor trafficking. J Biol Chem 277:30928-30934.

Yudowski GA, Puthenveedu MA, Leonoudakis D, Panicker S, Thorn KS, Beattie EC, von Zastrow M (2007) Real-time imaging of discrete exocytic events mediating surface delivery of AMPA receptors. J Neurosci 27:11112-11121.

Ziff EB (2007) TARPs and the AMPA receptor trafficking paradox. Neuron 53:627-633. 